\title{
A resolução online de litígios (ODR) de baixa intensidade: perspectivas para a ordem jurídica brasileira
}

\author{
The online dispute resolution (ODR): perspectives for brazilian legal order
}

\author{
Fernando Sérgio Tenório de Amorim*
}

\section{Resumo}

A relação entre a tecnologia e o Direito nem sempre se constituiu de maneira harmoniosa, dado o caráter conservador do primeiro e de sua necessidade de preservação das estruturas sociais; dadas as características disruptivas da tecnologia, que impõem à sociedade mudanças nos seus padrões de comportamento. Essa distonia entre regulação jurídica e desenvolvimento tecnológico traz a lume duas questões fundamentais: como estabelecer um diálogo entre o Direito e as novas tecnologias de informação sem que a ausência de neutralidade da tecnologia comprometa a formação de um quadro de regulação específico para o ciberespaço e para a resolução dos conflitos dele decorrentes? Como estabelecer um modelo de regulação online de litígios que enfrente o caráter ubíquo e desterritorializado do ciberespaço, reformulando os tradicionais conceitos de fronteiras geográficas e jurisdicionais tão caros ao Direito Internacional, em especial ao Direito Internacional Privado? A resolução online de conflitos pressupõe uma revisão da relação entre o Direito Interno dos Estados e o Direito Internacional. As soluções encontradas no âmbito de cada ordem jurídica estatal têm reflexos diretos no cenário internacional, sobretudo quando se tratam de relações jurídicas com conexão internacional. Esse é pano de fundo sobre o qual se descortinam as questões abordadas neste trabalho. Contrariamente à ciência, a tecnologia se desenvolve a partir de suas necessidades utilitárias, integrando-se à vida cultural, às obras do espírito e aos produtos industrializados sem qualquer preocupação de natureza moral ou ética. Do ponto de vista econômico e cultural, a tecnologia não é neutra, e sua propalada neutralidade constitui uma visão equívoca das suas funcionalidades. ODR consiste na utilização dos recursos da tecnologia para a Resolução Alternativa de Litígios (ADR). As possibilidades de utilização da tecnologia para a resolução de litígios são imensas, envolvendo questões complexas do ponto de vista teórico e tecnológico, como a utilização de inteligência artificial ou o uso das ferramentas de Dispute System Design (DSD). Sua aplicação exige do Direito Internacional Privado uma revisão das tradicionais teorias dos conflitos de leis e de jurisdições.

Palavras-chave: Resolução Online de Litígios (ODR). Direito Internacional Privado. Ciberespaço. Jurisdição. Normatividade.

\section{Abstract}

The relation between technology and law does not always constitute itself in a harmonious fashion, considering either the conservative nature of the latter and its need to preserve social structures or the characteristics of disruptive technology, requiring changes in the society pattern behavior. This dystonia between legal regulation and technological development brings to light two key issues: how to establish a dialogue between law and new information technologies without the lack of neutrality of technology compromising the formation of a specific regulatory framework for cyberspace and the resolution of deriving conflicts? How to establish an online dispute regulation model that addresses both the ubiquitous and deterritorialized cyberspace characters, reshaping the traditional concepts of geographic and jurisdictional boundaries so important to the International law, in particularly to Private International Law? The online conflict resolution requires a review of the relationship between the internal law of States and international law. The solutions found within each state law have a direct impact on the international stage, particularly when dealing with legal relations with international connection. This is the background on which the scope of this work is based. In opposition to science, technology develops from its utilitarian needs, integrating itself to the cultural life, to the works of the spirit and to the industrialized products without moral or ethical concerns. From an economic and cultural point of view, technology is not neutral, and his vaunted neutrality is an equivocal vision of its features. ODR consists in using the resources of technology for alternative dispute resolution. The possibilities of using the technology for resolving disputes are immense, involving complex issues from both theoretical and technological point of view, such as the use of artificial intelligence or the use of Dispute System Design tools (DSD). Its application requires from Private International Law a revision of the traditional theories of conflict of laws.

Keywords: Online Dispute Resolution (ODR). Private International Law. Cyberspace. Jurisdiction. Normativity.

\footnotetext{
Doutor em Direito pela Universidade Federal de Pernambuco - UFPE; Pós-Doutor pelo Laboratoire de Cyberjustice, Centre de Recherches en Droit Public, Université de Montréal, Canadá; Coordenador e Professor do Curso de Direito do Centro Universitário CESMAC, AL; Professor da Faculdade Sete de Setembro, BA; Procurador do Município de Maceió. Maceió - AL- Brasil. E-mail: fs.amorim@uol.com.br.
} 


\section{Introdução}

Os modelos tradicionais de resolução de litígios não fornecem as soluções mais eficazes para os problemas criados pela sociedade da informação. Com efeito, a utilização das novas tecnologias de informação e transmissão de dados mudou não apenas a economia mundial como transformou significativamente a maneira como os indivíduos estabelecem relações jurídicas. Longe de ser apenas mais uma ferramenta de comunicação, a Internet tornou-se o próprio espaço no qual se constituem inúmeras relações jurídicas, o que exige dos sistemas jurídicos nacionais uma nova abordagem sobre o velho problema da resolução de litígios. De um lado, a ubiquidade e a velocidade da formação das relações jurídicas no ciberespaço são a face mais evidente de uma ruptura com os meios tradicionais de contratualização e comercialização. Doutro lado, o desenvolvimento sem precedentes das novas tecnologias de transmissão de dados alterou em definitivo o Direito.

Os modos de Resolução Online de Litígios (Online Dispute Resolution - ODR) ${ }^{1}$ consistem, portanto, na utilização dos recursos da tecnologia para a Resolução Alternativa de Litígios - ADR, quer sejam estes decorrentes exclusivamente das relações jurídicas firmadas no ciberespaço, quer sejam originários de relações jurídicas constituídas no mundo dito "físico". Nesse sentido, ODR pode ser considerado espécie do gênero ADR. Mas seria demasiado simplista imaginar que os meios de Resolução Online Litígios sejam reduzidos a uma simples expressão dos meios de Resolução Alternativa de Controvérsias. As possibilidades de utilização da tecnologia para a resolução de litígios são imensas e envolvem questões complexas, tanto do ponto de vista teórico quanto sob o prisma tecnológico, como, por exemplo, a utilização de inteligência artificial para fornecer uma solução para o conflito ou mesmo o uso das ferramentas de Dispute System Design (DSD), aplicando-as aos meios de Resolução Online de Litígios. Sob uma perspectiva mais pragmática, os sistemas informatizados e as plataformas de transmissão e recepção de dados constituem um terceiro interveniente no processo de conciliação, ou até mesmo podem constituir um quarto sujeito, nos casos da mediação e da arbitragem online.

Tais questões ainda são pouco debatidas no Brasil, o que faz com que este estudo se revista de um caráter descritivo e exploratório. Seus objetivos não são, frise-se, constituir uma problematização específica sobre os meios de Resolução Online de Conflitos. Suas pretensões são bem mais modestas, restringindo-se a apresentar o desenvolvimento da teoria sobre o ODR e sua aplicação aos conflitos de baixa intensidade, ao tempo em que apresenta suas possibilidades de utilização no âmbito da ordem jurídica brasileira.

Este trabalho tratará, portanto, das características essenciais dos meios de Resolução Online de Litígios (ODR), apresentando o seu desenvolvimento histórico a partir de quatro experiências precursoras: o Virtual Magistrate Program, o Online Ombuds Office, o CyberTribunal e o Sistema de Resolução de Controvérsias sobre Nomes de Domínio na Internet (Uniform Dispute Resolution Policy - URDP) da ICANN (Internet Corporation for Assigned Names and Numbers); e três experiências contemporâneas: a proposta de regulamento de procedimento sobre a resolução online de litígios nas operações internacionais de comércio eletrônico, em discussão no Grupo de Trabalho III da United Nations Commission on International Trade Law (UNCITRAL); o Regulamento $n^{\circ}$ 524/2013, de 21 de maio de 2013, do Parlamento Europeu e do Conselho, relativo à resolução online dos conflitos de relação de consumo; e o Projeto PARLe, desenvolvido pelo Laboratoire de Cyberjustice do Centre de Recherches en Droit Public (CRDP) da Université de Montréal, no Canadá. Em seguida é apresentada uma visão prospectiva da utilização dos ODR na América Latina e no Brasil. Por fim, serão definidos alguns dos aspectos tecnológicos fundamentais dos sistemas ODR, como a sua relação com os Dispute Systems Design (DSD) e o uso da inteligência artificial.

\footnotetext{
Por questões de estilo, a sigla em inglês ODR (Online Dispute Resolution), consagrada pelo uso, será utilizada neste trabalho para representar, indistintamente, as expressões em português "Resolução Online de Litígios", Resolução Online de Conflitos" e "Resolução Online de Controvérsias, em razão do caráter intercambiável desses termos e sem prejuízo do rigor terminológico. De igual modo, a sigla em inglês ADR (Alternative Dispute Resolution) será utilizada para significar "Resolução Alternativa de Litígios", "Resolução Alternativa de Conflitos" e "Resolução Online de Controvérsias".
} 


\section{Os modos de resolução online de litígios (ODR): uma história recente}

Digressões históricas são sempre perigosas em trabalhos científicos, pois forçam o leitor a trilhar um caminho já conhecido e desbravado. Esse não é o caso, contudo, da Resolução Online de Litígios (ODR). O resgate da sua dimensão histórica é importante para a constituição de uma teoria de base para o ODR, em especial para que se possa efetuar uma distinção ontológica entre ODR e os meios de Resolução Alternativa de Litígios (ADR). O desenvolvimento das tecnologias de transmissão de dados e de informação transformou em definitivo a maneira como as pessoas se relacionam na sociedade em rede. As relações jurídicas firmadas no ciberespaço instauram uma nova forma de relacionamento com o real, criando outras fontes de normatividade e exigindo do Direito uma revisão dos seus paradigmas.

A resolução extrajudicial de litígios por meio da arbitragem, da conciliação ou da mediação não está, contudo, adstrita aos meios físicos de resolução de conflitos. O crescimento e a popularização das tecnologias de comunicação e informação (TI) propiciaram novas ferramentas para a resolução dos conflitos oriundos das relações jurídicas firmadas no ciberespaço. O movimento em direção aos meios de Resolução Online de Litígios (ODR) constitui-se, assim, num caminho natural para a resolução de conflitos que nascem das relações que os indivíduos estabelecem na Internet e nas demais redes de transmissão de dados e informação. Se tais conflitos assemelham-se às controvérsias comuns às relações jurídicas firmadas no mundo dito "físico", o caráter desterritorializado e ubíquo do ciberespaço impede uma simples transposição de regras materiais e procedimentais tradicionais para a resolução dos litígios virtuais.

A rede mundial de computadores transformou a forma como os indivíduos celebram negócios jurídicos, desconstituindo as fronteiras físicas e desterritorializando os contratos. Nada seria mais adequado para resolver os litígios oriundos dessas relações do que utilizar os mesmos recursos que as tecnologias de informação põem à disposição dos usuários da Internet. Com efeito, o relativo desenvolvimento dos meios online de resolução de litígios na América Latina é o resultado de uma mudança de mentalidade. Como afirmam com bastante propriedade Orna Rabinovich-Einy e Ethan Katsh (2014), "as novas tecnologias não aparecem apenas para mudar a forma como as pessoas fazem as coisas, elas alteram sobretudo a maneira como as pessoas pensam sobre o que estão fazendo, sobre o que precisa ser feito e o que pode ser realizado". ${ }^{2}$ Os meios de Resolução Alternativa de Litígios (ADR) trouxeram com eles uma nova mentalidade, extraindo do Poder Judiciário o monopólio da resolução de conflitos, transferindo-o para os particulares. Fenômeno semelhante irá ocorrer com os meios de Resolução Online de Litígios (ODR). Tais fenômenos são o reflexo direto das mudanças provocadas pela internacionalização da economia em escala global e, sobretudo, pela revolução causada com a aplicação das tecnologias de informação e comunicação ao mercado de bens e serviços.

A origem dos modos de Resolução Online de conflitos (ODR) está intimamente vinculada ao desenvolvimento dos meios de Resolução Alternativa de Controvérsias (ADR). É bem verdade que, desde o seu início, o novo espaço instituído pela Internet evocava uma gama enorme de possibilidades e um ambiente potencialmente tão lucrativo, do ponto de vista estritamente econômico, poderia gerar inúmeros conflitos. No entanto, ao lado do reconhecimento das imensas possibilidades da rede mundial de computadores, subjazia um certo ceticismo nos debates sobre a utilização dos recursos das tecnologias de informação e comunicação para a resolução de litígios. Como os meios tradicionais de resolução de controvérsias caracterizavam-se por uma comunicação face-à-face (face-to-face/F2F), fossem eles judiciais ou extrajudiciais, tais interações, no processo de troca de informações, não eram tão favorecidas pelos recursos tecnológicos, a despeito da sua imensa potencialidade.

Ethan Katsh foi um dos precursores na criação de uma teoria sobre os meios online de resolução de litígios. É de sua autoria um dos primeiros artigos sobre o tema, intitulado "Dispute Resolution in

"New technologies disrupt not only by changing how we do things but by changing how we think about what we are doing, about what needs to be done and what can be done. Alternative dispute resolution (ADR) was not simply a more efficient approach than what happened in court and, over time, it will be clear that ODR is not simply a more efficient process than ADR. ADR brought with it a new mindset, and so will ODR." 
Cyberspace", publicado na Conn. L. Rev. em 1996. Segundo o autor, o ceticismo inicial em relação à utilização da tecnologia na resolução de conflitos derivou do fato de que a Internet foi inventada em 1969 e, durante mais de 25 anos de sua existência, poucas disputas surgiram (KATSH, 2012, p. 09). O primeiro provedor de serviços na Internet (Internet Service Provider - ISP) apareceu em 1992 e até o início dos anos 1990 a National Science Foundation, órgão norte-americano responsável pela gestão da Internet, não autorizava a sua utilização para fins comerciais. Inexistiam disputas entre fornecedores e consumidores, por exemplo, em razão do simples fato de que tais atividades não eram exploradas na rede.

A última década do século $X X$ testemunhou o florescimento da Internet como um ambiente propício para a troca de dados em larga escala. A world wide web foi inventada em 1989. Nos anos que se seguiram, os provedores de serviços e os primeiros browsers de navegação, dos quais o Netscape era o mais popular, transformaram em definitivo a face da rede. Se nos primórdios de sua criação a Internet restringiase a um pequeno número de pessoas vinculadas a instituições militares e acadêmicas, no final do século XX a facilitação do acesso à rede possibilitou um aumento considerável da população online. Tais fatores conduziram a uma inevitável conclusão: ainda em 1994, parecia evidente que o ciberespaço não se tornaria um espaço harmonioso, sendo necessária a constituição de mecanismos e ferramentas para a resolução dos litígios que poderiam decorrer da atividade dos indivíduos na rede mundial de computadores (WAHAB; KATSH; RAINEY, 2012, p. 11). Os primeiros desses mecanismos surgiram ainda em 1996, constituindo-se em experiências precursoras do que hoje se denomina ODR.

\section{ODR: quatro experiências precursoras}

Nos idos do ano de 2001, Ethan Katsh e Janet Rifikin efetuavam uma divisão da história do ODR em três períodos. O primeiro período durou aproximadamente até 1995. Inexistia um número grande de disputas e os meios de resolução de litígios eram aplicados em contextos bastantes específicos. $O$ segundo período compreende os anos de 1995 a 1998, no quais se desenvolveu a compreensão de que a Internet necessitava de instituições online encarregadas da resolução dos conflitos que nasciam na rede. Várias experiências surgiram nessa fase, boa parte delas originária de universidades. O terceiro período começaria em 1998, caracterizando-se pela emergência de uma indústria do ODR e pelo reconhecimento de que as mesmas tecnologias empregadas na Resolução Online de Litígios poderiam ser utilizadas na resolução de controvérsias off-line (KATSH; RIFIKIN, 2001, p. 47). Quatro experiências podem ser, portanto, classificadas como precursoras dos sistemas de ODR.

\section{A) Virtual Magistrate Program}

O Virtual Magistrate Program (Programa Magistrado Virtual), criado em 1996 a partir de um encontro patrocinado, em 25 de outubro de 1995, pelo National Center for Automated Information Research (NCAIR) e pelo Cyberspace Law Institute (CLI) consistiu na primeira experiência mais próxima do que se poderia considerar, atualmente, um ODR (GELLMAN, 2015). O encontro ocorreu em Washington e teve como participantes: Timothy C. Leixner, NCAIR; Ann Sloane, NCAIR; Ellen Kirsh, America Online; William Marmon, MCI; David R. Johnson, CLI \& Counsel Connect; David Post, CLI \& Georgetown Law School; Robert Gellman, CLI Fellow \& Privacy and Information Policy Consultant; J. Beckwith Burr, CLI Fellow \& Federal Trade Commission; e George H. Friedman, American Arbitration AssociationEm linhas gerais, o Virtual Magistrate Program tinha como objetivo a Resolução Online de Litígios, pela via arbitral, para:

1. Estabelecer a viabilidade de utilização da Resolução Online de Litígios para os conflitos que se originam online;

2. Fornecer aos operadores de sistemas decisões fundamentadas e neutras, como respostas adequadas às reclamações sobre postagens supostamente ilícitas;

3. Fornecer aos usuários e a outros interessados uma solução rápida e de baixo custo para as reclamações efetuadas sobre postagens online; 
4. Estabelecer as bases para uma Resolução Online de Litígios autossustentável, como um recurso dos contratos firmados entre os operadores de sistema, os usuários e os fornecedores de conteúdo (e outros interessados em postagens ilícitas);

5. Ajudar a definir os deveres de um operador de rede quando confrontado com uma reclamação;

6. Explorar a possibilidade de utilizar o Virtual Magistrate Program para resolver outras disputas relacionadas a redes de computadores;

7. Desenvolver uma estrutura formal de governança para a operação do Magistrado Virtual. (BENYEKHLEF; GÉLINAS, 2005). ${ }^{3}$

A ideia central do Virtual Magistrate Program consistia em fornecer soluções para litígios que envolvessem usuários da Internet e os operadores de rede ou os provedores de acesso. Seu raio de abrangência, contudo, era bastante restrito, uma vez que o objetivo primeiro do programa era prevenir e fornecer soluções rápidas e eficazes para as controvérsias nas quais os próprios operadores de rede tinham interesse, o que os tornava simultaneamente juízes e partes na disputa (BENYEKHLEF; GÉLINAS, 2005). Todo o procedimento era efetuado pela troca de e-mails, nos quais restavam descritas as razões da reclamação, que em regra deveriam dizer respeito ao envio de mensagens e arquivos com conteúdo ilegal, violação de privacidade, apropriação ilícita de segredos comerciais, fraude, concorrência desleal, difamação ou postagem de material inadequado com conteúdo obsceno ou de ódio. O Virtual Magistrate comprometia-se a fornecer uma solução para o caso em até setenta e duas horas, cobrando dos interessados uma taxa de dez dólares americanos. O objetivo da fixação da taxa era evitar as reclamações indevidas ou sem fundamento.

Para os casos que ocorressem no mundo "físico", as partes submetiam-se voluntariamente a um procedimento arbitral. Para isso, o operador de rede poderia inserir a cláusula arbitral no contrato firmado com os usuários, o que nem sempre conferia força executória às decisões fornecidas pelo tribunal arbitral; ou, ainda, submeter-se unilateralmente às regras fixadas pelo árbitro. Em ambos os casos, ao árbitro competia decidir com base nas alegações sustentadas pelas partes e nas regras fixadas no contrato firmado entre os contendores, não Ihe sendo necessário aplicar de imediato uma norma jurídica originária de determinada jurisdição.

\section{B) Online Ombuds Office}

A segunda experiência precursora de ODR foi o Online Ombuds Office, implantado a partir de 1996 pelo Center for Information Technology and Dispute Resolution da Universidade de Massachusetts, nos Estados Unidos. O objetivo do programa era permitir a resolução de litígios que envolvessem questões relativas a disputas sobre nomes de domínios, provedores de acesso a Internet e seus usuários, propriedade intelectual ou grupos de discussão. $O$ traço diferencial desse projeto foi a utilização de textos, imagens e gráficos para auxiliar as partes no processo de resolução do litígio. A ideia de utilização dos recursos das tecnologias para facilitar o trabalho dos ombudsmen está centrada, como se verá adiante, no conceito de tecnologia como a "quarta" parte no processo de Resolução Online de Litígios.

Embora os recursos tecnológicos do Online Ombuds Office ainda não fossem tão avançados no momento da sua implantação, a simples possibilidade de transformar uma comunicação originariamente síncrona em comunicação assíncrona conferia às partes e ao mediador uma maior segurança na condução do processo de resolução da controvérsia. Numa comunicação síncrona, emissor e receptor têm de estar sincronizados, o que significa dizer que cada bloco de informação é transmitido num intervalo temporal previamente conhecido por ambos. Em contrapartida, na comunicação assíncrona os blocos de informação

\footnotetext{
"1. Establish the feasibility of using online dispute resolution for disputes that originate online; 2. Provide system operators with informed and neutral judgments on appropriate responses to complaints about allegedly wrongful postings; 3. Provide users and others with a rapid, low-cost, and readily accessible remedy for complaints about online postings; 4. Lay the groundwork for a self-sustaining, online dispute resolution system as a feature of contracts between system operators and users and content suppliers (and others concerned about wrongful postings); 5 . Help to define the reasonable duties of a system operator confronted with a complaint; 6. Explore the possibility of using the Virtual Magistrate Project to resolve other disputes related to computer networks; 7. Develop a formal governing structure for an ongoing Virtual Magistrate operation."
} 
não necessitam necessariamente ser enviados na mesma ordem e no mesmo intervalo temporal, bastando que contemplem a possibilidade de serem classificados e reordenados de maneira a não perderem o seu sentido original.

Transportando-se tais conceitos para a mediação online, a comunicação assíncrona fornece uma imensa gama de possibilidades para o mediador, uma vez que este pode estabelecer conversas paralelas, simultaneamente, com as partes, sem precisar reunir-se individualmente com cada uma delas, como ocorre nos processos físicos. Isso evita problemas de natureza prática, como, por exemplo, a gestão do tempo de encontro privado entre o mediador e cada uma das partes. Quando, numa reunião privada, o mediador dedica mais tempo a uma das partes do que à outra, essa diferença pode ser interpretada negativamente. Tal problema inexiste na mediação realizada online, pois os algoritmos permitem que as conversas com o mediador sejam estabelecidas concomitantemente, sem que as partes tomem conhecimento disso. A tecnologia funciona, portanto, como uma quarta parte que é posta à disposição das partes contendoras:

A quarta parte pode assistir as partes de várias formas na medida em que caminham em direção à resolução. Por exemplo, a quarta parte pode fornecer informações e estabelecer as expectativas das partes de uma maneira imparcial, o que não é possível à terceira parte. Os algoritmos de softwares podem também permitir uma variedade de diferentes tipos de comunicação, de textos baseados em conversações assíncronas (como o e-mail), a textos baseados em conversações síncronas (como o chat). Softwares podem também permitir conversas por meio de ferramentas como o Skype e o Google Hangouts. Tais ferramentas podem permitir a participação de indivíduos de qualquer parte do mundo, economizando tempo e despesas de viagens e ampliando a participação e o engajamento dos litigantes $^{4}$ (RULE; SEN, 2015, p.76).

\section{C) CyberTribunal}

A terceira experiência precursora de ODR merecedora de destaque foi o CyberTribunal, implantado em setembro de 1996 pelo Centre de Recherches en Droit Public da Université de Montréal, no Canadá. O principal objetivo do projeto consistia na prevenção e resolução online de litígios ocorridos na Internet, utilizando para tanto o recurso à mediação e à arbitragem. O CyberTribunal possuía, portanto, um campo de atuação bem mais amplo do que o das experiências do Virtual Magistrate e do Online Ombuds Office, a despeito do fato de restar adstrito à resolução dos conflitos oriundos exclusivamente da Internet. É importante ressaltar que o CyberTribunal não se convertia em juiz dos casos submetidos à sua apreciação, não assumindo uma função jurisdicional, ou ao menos não o fazendo nos moldes do exercício da jurisdição estatal. As partes voluntariamente submetiam o conflito à apreciação do CyberTribunal, composto por juristas e não juristas com formação em mediação, arbitragem e direito das tecnologias de informação, competindo aos mediadores e árbitros conduzir o processo de maneira segura e sigilosa (BENYEKHLEF; GÉLINAS, 2005).

O sítio na Internet do CyberTribunal dividia-se em quatro seções ou módulos distintos: recepção, mediação, arbitragem e Secretaria. No módulo recepção, o usuário tinha acesso às informações básicas sobre o funcionamento do sistema, bem como aos formulários que permitiriam a abertura de um processo. Uma vez preenchido com as informações necessárias para o andamento da demanda, como a qualificação das partes, a natureza e o objeto do litígio, bem como a solução pretendida, o formulário era então codificado e enviado à Secretaria. Esta última se encarregava da designação de um mediador que, tendo recebido o dossiê, comunicava-se com o demandado, apresentando-lhe o processo e convidando-o a participar da mediação. A atuação do mediador era precedida de uma tentativa prévia de conciliação entre as partes que, diante da inexistência de conciliação, decidiam voluntariamente submeter-se à mediação ou à arbitragem.

\footnotetext{
$4 \quad$ "The fourth party can assist parties in a variety of ways as they move toward resolution. For example, a fourth party can provide information and set expectations for the parties in an impartial way that a third party cannot. Software algorithms can also enable a variety of different types of communication, from text-based asynchronous conversations (such as e-mail) to text-based synchronous conversations (such as chat). Software can also enable audio and video conversations via tools such as Skype and Google Hangouts. These tools can enable participation from individuals anywhere in the world, saving them the time and expense of travel, and increasing the participation and engagement of disputants."
} 
O módulo arbitragem, por seu turno, operava de forma semelhante ao módulo mediação, dele diferindo apenas em razão da aplicação de regras de procedimento mais rígidas. Tais regras adotavam como modelo os regulamentos de arbitragem da United Nations Commission on International Trade Law (UNCITRAL) e da Chambre de Commerce Internationale (CCI). O projeto CyberTribunal terminou em 1999, tendo resolvido mais de uma centena de litígios e utilizado, de forma pioneira, a mediação e a arbitragem na resolução online de litígios. Todas essas experiências constituíram o ponto de partida para a criação de plataformas mais sofisticadas de resolução online de conflitos. Dessas plataformas, o sistema de resolução desenvolvido pelo sítio e-Bay é sem dúvida o mais eficaz, tendo resolvido mais de 60 milhões de disputas entre seus usuários.

D) Sistema de Resolução de Controvérsias sobre Nomes de Domínio na Internet (Uniform Dispute Resolution Policy - URDP) da ICANN (Internet Corporation for Assigned Names and Numbers)

O Sistema de Resolução de Controvérsias sobre Nomes de Domínio na Internet desenvolvido, em 1999, pela ICANN (Internet Corporation for Assigned Names and Numbers), constitui a quarta experiência pioneira de ODR digna de registro. O sistema, denominado UDRP (Uniform Dispute Resolution Policy), tem por objetivo regular os conflitos existentes sobre atribuição de nomes de domínio na Internet. O UDRP foi o primeiro sistema verdadeiramente transnacional de resolução online de conflitos. O objetivo principal da ICANN, uma instituição sem fins lucrativos, consiste não apenas em regular a atribuição dos nomes de domínio na Internet como também evitar o registro indevido desses nomes.

No início do desenvolvimento da rede mundial de computadores, as empresas cujas marcas apresentavam o alto valor econômico e de mercado por vezes tinham de desembolsar elevadas somas de dinheiro para "resgatar" um nome de domínio que ostentasse a sua marca. Como o sistema de registro de domínios fundava-se no princípio "first-come, first-served", ou seja, quem por primeiro registrasse o domínio teria a exclusividade na sua utilização, nomes de domínios de marcas famosas foram registrados por particulares antes mesmo que as empresas detentoras dessas marcas pensassem em registrar seus sítios na Internet. Um lucrativo mercado foi criado com base nessa prática (RULE, 2002, p. 204), pois as empresas precisaram adquirir os direitos de uso do domínio já registrado, fazendo com que um nome de domínio no qual foram gastos apenas alguns dólares para o registro fosse vendido por alguns milhares ou, até mesmo, milhões de dólares.

O procedimento de resolução de litígios da ICANN tem por objetivo, portanto, resolver as controvérsias envolvendo o registro indevido de nomes de domínio e, com isso, estabelecer uma distinção clara entre o registro legal do domínio e a prática do "cybersquatting", que consiste em registrar um domínio com a finalidade única de vendê-lo posteriormente. A ICANN (2012) adota uma Política para Resolução Uniforme de Litígios sobre Nome de Domínio, na qual são estabelecidos os princípios gerais para a resolução dos conflitos, e um conjunto de Regras de Procedimento. Atualmente estão igualmente em vigor duas regras de procedimento distintas. Uma aplicável às denúncias efetuadas até 30 de julho de 2015, e outra incidente sobre as denúncias realizadas a partir de 31 de julho de 2015 (ICANN, 2015), embora os Provedores de Serviço de Resolução de Disputas possam decidir aplicar as regras mais recentes a todos os procedimentos, além de poderem adotar regras suplementares.

Atualmente são cinco os Provedores de Serviço de Resolução de Disputas credenciados junto ao ICANN: Asian Domain Name Dispute Resolution Centre, National Arbitration Forum, World Intelectual Property Organisation (WIPO), The Czech Arbitration Court Arbitration Center for Internet Disputes e Arab Center for Domain Name Dispute Resolution (ACDR).

Um dos segredos do sucesso do sistema URDP reside no caráter executável de suas decisões, o que nem sempre é possível para outros sistemas de ODR. Ume vez decidida a controvérsia, a ICANN deve efetuar a alteração na sua base de dados para atribuir o nome de domínio ao seu legítimo detentor. Esse controle absoluto da base de dados favorece a força executória da decisão proferida, propiciando-lhe uma eficácia verdadeiramente transnacional. Outros sistemas de ODR não possuem a mesma eficácia, 
uma vez que lhes é impossível ter bases em todos os lugares nos quais a decisão deveria produzir os seus efeitos.

O aparente monopólio da ICANN na atribuição de nomes de domínio foi contestado por empresas, como a "New.net", que chegou a oferecer inúmeras extensões de domínio como .travel, .kids, .club, .family etc. Essas extensões deixaram de existir quando entraram em conflito com as extensões já registradas na ICANN. A New.net aparentemente encerrou suas atividades em 2012, após envolver-se inúmeras controvérsias judiciais, dentre as quais o caso State of Connecticut v. Julie Amero. Nesse caso, a professora Julie Amero foi inicialmente condenada a 40 anos de prisão por supostamente acessar sites pornográficos diante dos seus alunos, em Norwich, Connecticut, EUA. A sentença foi posteriormente revisada, mas Julie Amero perdeu as credenciais de professora. Uma perícia criminal constatou que o computador da professora Amero havia sido vítima de um DNS hijacking, um código malicioso que redireciona o DNS da máquina. O redirecionamento do navegador para páginas pornográficas teria sido supostamente efetuado pelo programa NewDotNet, fornecido pela NewNet. ${ }^{5}$

As transformações sofridas pelos ODR ao longo das últimas décadas estão intimamente associadas ao desenvolvimento das tecnologias de informação e comunicação. Com novas tecnologias postas à disposição dos usuários da rede, surge uma imensa gama de novos problemas que exigem dos sistemas de Resolução Online de Litígios o aprimoramento das suas plataformas e procedimentos com o objetivo de garantir a conveniência, o conhecimento e a confiança na resolução dos conflitos originários do ciberespaço. Esses três pilares fundantes do ODR são o ponto de partida de todo o processo de resolução online de litígios e estão na base do desenvolvimento de qualquer sistema de resolução online de controvérsias (KATSH; RIFIKIN, 2001, p. 74). Para tanto, tais sistemas precisam lidar com as noções de ubiquidade e desterritorialização próprias do ciberespaço, em especial quando se está a tratar de litígios que, por apresentarem um elemento de extraneidade, vinculam-se a ordenamentos jurídicos distintos e, por consequência, poderiam ser submetidos jurisdições estatais também distintas. A velha teoria do conflito de leis e de jurisdições, tão cara ao Direito Internacional Privado, está, como se verá adiante, posta à prova. Antes, porém, convém apresentar algumas perspectivas atuais para a utilização dos sistemas de Resolução Online de Litígios no cenário internacional.

\section{ODR: três experiências contemporâneas}

Três experiências contemporâneas de caráter internacional, duas das quais ainda em elaboração, ilustram as dificuldades enfrentadas no desenvolvimento dos meios de Resolução Online de Conflitos. A primeira dessas experiências parece estar, infelizmente, fadada ao malogro ${ }^{6}$ (VERMEYS, 2015).

\section{A) Proposta de regulamento de procedimento sobre a resolução online de litígios nas operações internacionais de comércio eletrônico da UNCITRAL}

A proposta de regulamento de procedimento sobre a resolução online de litígios nas operações internacionais de comércio eletrônico, em discussão no Grupo de Trabalho III da United Nations Commission on International Trade Law (UNCITRAL) tem enfrentado, desde o seu nascedouro, inúmeras dificuldades para aprovação. O projeto teve início ainda no ano de 2010. Durante a quadragésima terceira reunião da UNCITRAL, realizada em New York, no período de 21 de junho a 09 de julho, a Comissão resolveu instituir um grupo de trabalho encarregado de realizar estudos sobre a questão da resolução online de conflitos nas operações internacionais do comércio eletrônico, em especial nas operações entre empresas e entre empresas e consumidores. A decisão foi tomada em razão da constatação, pela Comissão, em

\footnotetext{
5 Para mais informações sobre o caso consulte-se: < http://julieamero.blogspot.ca/> e < http://www.jud2.ct.gov/crdockets/CaseDetailDisp. aspx?source=Pending\&Key=ffde4134-6a67-49e9-bac5-4a9b0b4029b5>.

6 O autor agradece ao Prof. Nicolas Vermeys, Professeur Agrégé à la Faculté de Droit de l'Université de Montréal, Directeur Adjoint du Laboratoire de Cyberjustice e Chercheur au Centre de Recherches en Droit Public-CRDP, pela cessão do texto ainda inédito.
} 
encontro realizado em Viena, na Áustria, em 29 e 30 de março de 2010, que os mecanismos clássicos de recurso ao Poder Judiciário não constituíam uma solução adequada para os casos dos litígios relativos ao comércio eletrônico internacional. Segundo a Comissão, a solução para esses litígios residia talvez em um sistema mundial de resolução online de conflitos entre empresas e entre empresas e consumidores. Tais litígios deveriam ter por objeto pequenos valores e ocorrer em larga escala. Ressalta-se que todos os documentos de trabalho do Grupo de Trabalho III estão disponíveis na página web da UNCITRAL.

O objetivo principal do projeto está fundado basicamente na ideia de simplicidade e de viabilidade econômica do acesso à justiça. Com efeito, relegar aos tribunais estatais a possibilidade de decidir um litígio que envolva um pequeno valor econômico e monetário diminui imensamente a possibilidade de que tal conflito seja efetivamente submetido ao Poder Judiciário. Assim ocorre porque o consumidor que adquire online um produto, que lhe será entregue numa operação internacional, irá obrigatoriamente mensurar os aspectos econômicos da submissão, a um tribunal estrangeiro, de um conflito decorrente de um eventual inadimplemento contratual. Tratando-se da compra de um objeto de menor valor monetário, resta evidente que entre a perda econômica do preço do objeto e os elevados custos de um processo que tramitará em um tribunal no exterior, o consumidor não hesitará em assumir o prejuízo econômico.

A proposta da UNICTRAL esbarra, assim, em inúmeros problemas. O primeiro deles diz respeito à adequação dos procedimentos de ODR com as regras de Direito Internacional Privado dos países, em especial no que concerne à determinação da lei aplicável ao litígio e, eventualmente, à fixação da jurisdição competente. O segundo problema consiste na relação entre o sistema de resolução de conflitos e as normas imperativas internas dos países, cuja aplicação é mandatória e precede a própria utilização das regras de conflito do Direito Internacional Privado. Por fim, tem-se a inevitável discussão sobre o reconhecimento e execução, no âmbito doutras jurisdições estatais, das decisões proferidas pelo sistema de resolução online de litígios. Ronald Brand lista esses problemas como o ponto central na análise por ele efetuada da aplicação do princípio da autonomia da vontade (Party autonomy) ao projeto da UNCITRAL:

\begin{abstract}
As questões mais difíceis nas negociações de ODR estão centradas em conceitos que levantam problemas importantes sobre a coordenação dos procedimentos de ODR com as regras nacionais de Direito Internacional Privado (conflito de leis), as regras nacionais de proteção dos consumidores e o quadro legal sobre a arbitragem internacional. Qualquer sistema global de ODR que pretenda ser bem sucedido deve evitar as difíceis questões sobre a aplicação das normas imperativas nacionais, deve ser concebido para fornecer procedimentos justos com resultados efetivos para os consumidores e os resultados obtidos devem ser reconhecidos através das fronteiras. Isso só acontecerá se o sistema respeitar a capacidade individual das partes (independentemente da categoria) para firmar acordos vinculativos de ODR no momento em que celebram o contrato para uma transação online. ${ }^{7}$ (BRAND, 2012).
\end{abstract}

Some-se a essas dificuldades o fato de que o resultado final da iniciativa da UNCITRAL não assume o caráter de uma convenção ou tratado internacional, caracterizando o que os internacionalistas convencionaram denominar soft-law. Como não possui um caráter coercitivo, o projeto de resolução online de litígios perde muito do seu vigor, pois o seu eventual sucesso estaria inteiramente associado à possibilidade de as partes livremente elegerem o ODR como a via indicada para a resolução do conflito. A ideia de autonomia da vontade é, portanto, subjacente ao projeto de resolução online de litígios da UNCITRAL. E esse é um dos principais pontos que entravam a aprovação do projeto.

Muitos países não aceitam o procedimento arbitral instituído por meio de cláusula compromissória inserida nos contratos de consumo. Por essa razão, o Grupo de Trabalho acatou a sugestão de elaborar um texto consagrando duas vias. A Via I conduziria à arbitragem obrigatória, a Via II, não. Ainda assim,

\footnotetext{
"The most difficult issues in the ODR negotiations are centered on concepts raising important questions about the coordination of the ODR process with national rules of private international law (conflict of laws), national rules of consumer protection, and the international arbitration law framework. If any global system of ODR is to be successful, it must avoid difficult questions about the application of national mandatory rules of law, it must be considered to provide fair procedures and results for consumers, and the results obtained must be enforceable across borders. This will only happen if the system respects the ability of individual parties (regardless of category) to enter into binding ODR agreements at the time they form the basic contract for an online transaction."
} 
não se pode afirmar que os trabalhos avançam de maneira significativa. As divergências existentes no tratamento dado à proteção do consumidor na Europa e nos Estados Unidos dificultam a adoção de um texto que contemple essas diferenças.

Existem, também, dúvidas com relação à aplicação ou não da Convenção de New York sobre - Reconhecimento e a Execução de Sentenças Arbitrais Estrangeiras, de 1958, promulgada no Brasil pelo Decreto $n^{\circ} 4.311$, de 23 de julho de 2002, uma vez que os custos elevados do reconhecimento das sentenças arbitrais, tal como referidas na Convenção de New York, inibiriam a execução das decisões oriundas da resolução online de litígios versando sobre causas de pequeno valor econômico. Além disso, na 31 ${ }^{\text {a }}$ Sessão do Grupo de Trabalho, as delegações dos Estados Unidos e da Colômbia apresentaram uma proposta conjunta de análise da retro-faturação como um mecanismo de proteção do consumidor a ser associado ao projeto de resolução online de litígios da UNCITRAL. A possibilidade que tem o consumidor de obter a devolução dos valores pagos em caso de eventual inadimplemento contratual não está adstrita apenas aos cartões de crédito. Em casos que envolvem pequenas quantias, a simples devolução do dinheiro já satisfaz o consumidor, evitando-se assim gastos desnecessários com um procedimento de Resolução Online de Controvérsias.

\section{B) Regulamento $n^{\circ}$ 524/2013 do Parlamento Europeu e do Conselho, relativo à resolução online dos conflitos de relação de consumo}

O Regulamento n 524/2013, de 21 de maio de 2013, do Parlamento Europeu e do Conselho, relativo à resolução online dos conflitos de relação de consumo cria um quadro de regulação para os litígios que envolvam profissionais e consumidores no âmbito da União Europeia, constituindo uma importante experiência de utilização dos meios de Resolução Online de Litígios, embora o modelo proposto no Regulamento não se enquadre perfeitamente na definição mais clássica de ODR. De todo modo, a análise do Regulamento $n^{\circ}$ 524/2013 torna-se relevante em razão da importância econômica da União Europeia, da necessidade de harmonização da imensa pluralidade legislativa do Continente e, principalmente, da constituição de um sistema online de resolução de conflitos fundado na preservação da concepção, tão cara aos europeus, de proteção do consumidor.

O Regulamento objetiva a criação de uma plataforma online de resolução de litígios que abranja todos os países membros da União Europeia, baseando-se na concepção de que o desenvolvimento do mercado interno no âmbito do bloco europeu está intimamente associado às relações de consumo e, em especial, às relações de consumo online:

(18) O presente regulamento tem por objetivo criar uma plataforma de RLL à escala da União. Esta plataforma deverá assumir a forma de um sítio interativo, com um ponto de entrada único para os consumidores e para os comerciantes que pretendam resolver litígios decorrentes de transações em linha por via extrajudicial. Deverá ainda prestar informações gerais sobre a resolução extrajudicial de litígios em matéria contratual entre consumidores e comerciantes resultantes de contratos de venda e de serviços em linha. Deverá permitir que os consumidores e os comerciantes apresentem queixas utilizando um formulário eletrônico disponível em todas as línguas oficiais das instituições da União, e lhe juntem os documentos relevantes. Deverá transmitir as reclamações a uma entidade de RAL competente para conhecer do litígio em causa. A plataforma de RLL deverá disponibilizar uma ferramenta eletrônica de gestão gratuita que permita às entidades de RAL conduzir o procedimento de resolução de litígios em linha com as partes através da plataforma de RLL. As entidades de RAL não deverão ser obrigadas a utilizar a ferramenta de gestão.

A preservação da segurança e da confiança nas relações contratuais online constitui uma preocupação do Parlamento Europeu e do Conselho, o que justifica a adoção de um sistema de resolução extrajudicial de conflitos mediante a criação de uma plataforma de Resolução Online de Litígios (Résolution en Ligne de Litiges - RLL) que facilite a solução independente, imparcial, transparente, eficaz, rápida e justa dos conflitos que envolvam consumidores e profissionais, conforme estabelece o Art. $1^{\circ}$ do Regulamento. Alguns requisitos, no entanto, precisam ser observados para que o Regulamento possa ser aplicado. 
Nicolas Vermeys (2015) menciona a necessidade de se preencherem conjuntamente três critérios: material, tecnológico e geográfico para que se possa admitir a incidência do Regulamento.

De acordo com o critério material, é necessário que se esteja diante de uma resolução extrajudicial de litígio concernente a uma relação contratual firmada entre um consumidor e um profissional. Com efeito, a plataforma de RLL deverá basear-se em uma das entidades de Resolução Alternativa de Litígios (RAL, na denominação dada pelo Regulamento), já existentes nos Estados-Membros da União Europeia, que aplicarão ao litígio as suas próprias regras procedimentais. O sentido aqui atribuído à expressão resolução extrajudicial de litígios é bastante largo, podendo abranger entidades que forneçam diretamente uma solução para o caso ou que tenham por objetivo apenas reunir os contendores para facilitar a resolução amigável do conflito por meio da negociação, da mediação ou da arbitragem (VERMEYS, 2015). Essa é, talvez, uma das fragilidades do Regulamento: a necessidade de se adequar às regras nacionais de resolução extrajudicial de litígios. Como o Regulamento também permite as reclamações iniciadas por um comerciante contra um consumidor, é necessário que a legislação do país em que domiciliado o consumidor aceite que esse litígio seja submetido a um procedimento de resolução extrajudicial, competindo aos Estados-Membros informar à Comissão se essa possibilidade é admitida em sua legislação interna.

O segundo critério é o tecnológico. O objeto do litígio deve versar sobre um contrato eletrônico de compra e venda ou de prestação online de serviços. O Regulamento exclui do seu campo de incidência os conflitos que versem sobre contratos firmados no mundo "físico", ou ainda os contratos firmados entre comerciantes:

(14) A definição de "contrato de venda ou de serviços em linha" deverá abranger um contrato de venda ou de serviços em que o comerciante, ou o seu intermediário, oferece, num sítio ou através de outros meios eletrônicos, bens ou serviços que o consumidor encomenda no mesmo sítio ou através de outros meios eletrônicos. Esta definição deverá abranger igualmente os casos em que o consumidor acede ao sítio ou a outros serviços próprios da sociedade da informação através de um dispositivo eletrônico móvel como, por exemplo, um telemóvel.

O terceiro critério, geográfico, é o mais controverso. Tanto os consumidores quanto os profissionais devem ser residentes e estar estabelecidos no âmbito da União Europeia. A vinculação das partes no litígio a um determinado território vai de encontro à própria natureza das relações online, desconhecendo o caráter desterritorializado do ciberespaço.

Não se pode afastar a possibilidade de que o profissional possua raízes fora da União Europeia ou mesmo que o prestador de serviços de Resolução Alternativa de Litígios (RAL), ao qual o procedimento será submetido, não esteja situado no território da União Europeia. Esses três critérios precisam ser preenchidos conjuntamente para que se possa aplicar o Regulamento $n^{\circ}$ 524/2013.

No entanto, a plataforma RLL desenvolvida e gerida pela União Europeia não assume as características de uma plataforma online de resolução de conflitos, ao menos não nos moldes tradicionais. Trata-se, na verdade, de um centro de recepção e triagem dos conflitos, que em seguida serão remetidos às entidades de Resolução Online de Litígios. Do ponto de vista prático, muitos problemas precisam ser suplantados. A plataforma fornecerá um formulário a ser preenchido pelo interessado, no qual deverão ser apresentadas as razões da reclamação, e esse formulário deverá estar disponível em todos os idiomas oficiais da União Europeia:

\section{CAPÍTULO II \\ PLATAFORMA DE RLL \\ Artigo $5^{\circ}$ \\ Criação da plataforma de RLL}

1. A Comissão cria uma plataforma de RLL e é responsável pelo seu funcionamento, incluindo todas as funções de tradução necessárias ao objetivo do presente regulamento, à sua manutenção, ao seu financiamento e à segurança dos dados dela constantes. A plataforma de RLL deve ser de fácil utilização. A criação, o funcionamento e a manutenção da plataforma de RLL devem assegurar que 
a privacidade dos seus utilizadores seja respeitada desde a fase de concepção, e que a plataforma de RLL seja acessível e utilizável por todos os utilizadores, incluindo, na medida do possível, os utilizadores vulneráveis.

2. A plataforma de RLL deve constituir um ponto único de entrada para os consumidores e os comerciantes que pretendam obter a resolução extrajudicial dos litígios abrangidos pelo presente regulamento. Deve ser um sítio interativo, gratuito e acessível em linha em todas as línguas oficiais das instituições da União.

3. A Comissão deve tornar a plataforma de RLL acessível, conforme adequado, através dos seus sítios na Internet que prestam informações aos cidadãos e às empresas na União e, em particular, através do portal "A sua Europa”, criado de acordo com a Decisão 2004/387/CE.

4. A plataforma de RLL tem as seguintes funções:

a) Disponibilizar um formulário eletrônico que pode ser preenchido pelo autor da queixa nos termos do artigo $8^{\circ}$;

b) Informar a parte requerida sobre a queixa;

c) Identificar a entidade ou entidades de RAL competentes e transmitir a queixa à entidade de RAL a que as partes decidiram recorrer de comum acordo, nos termos do artigo $9^{\circ}$;

d) Disponibilizar uma ferramenta eletrônica de gestão gratuita que permita às partes e à entidade de RAL conduzir o procedimento de resolução de litígios em linha através da plataforma de RLL;

e) Disponibilizar às partes e à entidade de RAL a tradução das informações necessárias à resolução do litígio, trocadas através da plataforma de RLL;

f) Disponibilizar um formulário eletrônico através do qual as entidades de RAL transmitam as informações referidas no artigo $10^{\circ}$, alínea c);

g) Disponibilizar um sistema de retroação que permita às partes exprimirem os seus pontos de vista sobre o funcionamento da plataforma de ODR e sobre a entidade de RAL que tratou do seu litígio;

h) Facultar ao público os seguintes elementos:

i) informações de caráter geral sobre a RAL como meio de resolução extrajudicial de litígios,

ii) informações relativas às entidades de RAL inseridas numa lista nos termos do artigo $20^{\circ}, n^{\circ} 2$, da Diretiva 2013/11/UE competentes para tratar os litígios abrangidos pelo presente regulamento,

iii) um guia em linha sobre a forma de apresentar as queixas através da plataforma de RLL,

iv) informações, incluindo as coordenadas, sobre os pontos de contacto de RLL designados pelos Estados-Membros nos termos do artigo $7^{\circ}, \mathrm{n}^{\circ} 1$, do presente regulamento,

v) dados estatísticos sobre o resultado dos litígios transmitidos às entidades de RAL através da plataforma de RLL.

Em seguida, a plataforma encaminhará o formulário a uma das entidades provedoras de serviços Resolução Alternativa de Litígios (RAL). As dificuldades operacionais podem desencorajar consumidores e comerciantes a submeterem os litígios à plataforma.

\section{C) Projeto PARLe do Laboratoire de Cyberjustice do Centre de Recherches en Droit Public (CRDP) da Université de Montréal}

A terceira experiência contemporânea de ODR que merece registro é o Projeto PARLe, em desenvolvimento pelo Laboratoire de Cyberjustice do Centre de Recherches en Droit Public (CRDP) da Université de Montréal, no Canadá. O PARLe consiste numa plataforma de resolução online de conflitos de baixa intensidade criada pelos profissionais do Laboratoire de Cyberjustice da UdeM. O projeto inserese em um dos vários eixos de pesquisa do Laboratoire e do CRDP sobre as relações entre o Direito e as novas tecnologias de informação e transmissão de dados.

O projeto PARLe é o resultado de uma preocupação do Laboratoire de Cyberjustice com os resultados práticos dos estudos e pesquisas realizados no âmbito do Laboratório. Seu objetivo principal é desenvolver uma ferramenta que possibilite um fácil acesso à justiça por parte dos cidadãos, em especial nos casos de litígios de baixa intensidade, ou seja, litígios que ocorrem em larga escala e versam sobre pequenas somas de dinheiro. O PARLe baseia-se, portanto, numa abordagem que consagra três grandes 
princípios: 1) Colaborativo: levando em conta as necessidades das partes envolvidas durante a concepção e implementação do projeto, promovendo e estimulando a sua adoção; 2) Público: propugnando a integração com o Poder Judiciário e com os demais atores estatais, garantindo-se uma operação sob a proteção da lei; 3) modular: priorizando uma abordagem com base numa experiência-piloto, permitindo a realização de testes e ajustando gradualmente a implantação do projeto (CRDP/LABORATOIRE DE CYBERJUSTICE, 2015).

Aideia central é levar o projeto aos países da América Latina, constituindo parcerias institucionais com os poderes públicos, as universidades e a iniciativa privada, com o objetivo de partilhar os conhecimentos e as ferramentas tecnológicas desenvolvidas pelo Laboratório para auxiliar os cidadãos na defesa de seus interesses:

\begin{abstract}
O objetivo comum é levar um conjunto de experiências, tecnologias, conhecimentos e ideias às partes interessadas a fim de fortalecer a governança e ampliar o acesso à justiça e ao desenvolvimento sustentável nos países latino-americanos. Os parceiros institucionais irão compartilhar esse conhecimento e desenvolver um projeto-piloto que visa a construção de sociedades pacíficas e inclusivas em todos os níveis, promovendo o Estado de direito e reforçando o acesso à justiça para os grupos sociais mais vulneráveis: um propósito em consonância com os objetivos estabelecidos pela Organização das Nações Unidas no UN Sustainable Developement Gol. (CRDP/LABORATOIRE DE CYBERJUSTICE, 2015).
\end{abstract}

O PARLe destina-se, sobretudo, a ser aplicado nos países em desenvolvimento, nos quais fatores como os custos e a complexidade dos procedimentos judiciais, retardos nos julgamentos das ações e ausência de conhecimento da população sobre o direito de ação findam por gerar um ceticismo em relação à eficiência do sistema estatal de prestação jurisdicional. Como os meios judiciais ainda predominam como via adotada para a resolução de conflitos, a submissão dos casos mais simples aos meios de Resolução Alternativa de Litígios (ADR) deixaria o Poder Judiciário mais livre para tratar das questões mais complexas, reduzindo assim os atrasos e a ineficiência da prestação jurisdicional estatal. O programa apresenta, portanto, como objetivo final e objetivos intermediários:

\footnotetext{
Objetivo final: melhorar o acesso à justiça para os grupos sociais vulneráveis na América Latina, reduzindo as desigualdades de classe no âmbito do Estado de Direito e ampliando a coesão social através da renovação da confiança dos cidadãos nas instituições judiciais, em especial quando transacionam com outros cidadãos.

Objetivo intermediário 1: aumento do número de conflitos de baixa intensidade resolvidos pelos cidadãos, sob a proteção da lei, levando a autorrealização e ao aumento da confiança nas instituições judiciais.

Objetivo intermediário 2: aumento da capacidade de resposta das instituições judiciais para as diversas necessidades dos cidadãos, em especial no que concerne à obtenção do direito de acesso à justiça pelos grupos sociais vulneráveis, por meio do uso eficiente da tecnologia.

Objetivo intermediário 3: aumento do uso da tecnologia pelas pessoas, em especial pelos grupos sociais vulneráveis, com o objetivo de melhorar o acesso à justiça, a participação da sociedade civil e o engajamento na vida democrática. (CRDP/LABORATOIRE DE CYBERJUSTICE, 2015).
}

Como se observa, o PARLe constitui muito mais do que a simples adoção de uma plataforma de Resolução Online de Conflitos. Trata-se, na verdade, de uma tentativa de se desenvolver uma cultura de submissão de litígios aos sistemas de (ODR), uma vez que o projeto defende o envolvimento da população local e de atores institucionais vinculados aos poderes públicos e à iniciativa privada. Essa simbiose entre atores estatais, instituições privadas, universidades e cidadãos permite o desenvolvimento de uma política contínua de avaliação e aprimoramento do projeto, uma vez que "o estudo dos impactos a longo prazo do uso do ODR fornece informações valiosas para que se possam ajustar as políticas públicas ao direito universal de acesso à justiça" (CRDP/LABORATOIRE DE CYBERJUSTICE, 2015).

O fato de o projeto PARLe voltar-se para América Latina revela sua principal virtude ao tempo em que descortina a sua maior fraqueza. Seu principal desafio resulta na adequação da plataforma à realidade econômico-social dos países latino americanos, o que não se constitui em tarefa fácil de ser executada. 
Deve-se levar em conta o grau de acesso da população, sobretudo da população de baixa renda, às tecnologias da informação e comunicação, além do grau de instrução dessa população no que diz respeito ao exercício dos seus direitos fundamentais. De todo modo, como se verá adiante, a América Latina tem se mostrado um campo promissor para a utilização dos modos de Resolução Online de Litígios (ODR).

\title{
5 ODR: uma perspectiva brasileira
}

Algumas afirmações tornam-se lugares comuns e, como tais, são repetidas à exaustão até se consolidarem como verdades absolutas, sem que alguém se preocupe em lhes questionar as origens ou testar empiricamente os seus postulados. Uma dessas verdades decorria da afirmação de que os meios de Resolução Alternativa de Litígios (ADR) não prosperariam na América Latina - em especial no Brasil em virtude da tradição continental de submeter todos os litígios ao juiz estatal. Essa afirmação, contudo, traduz apenas a uma meia-verdade.

Se, por um lado, não se pode desconsiderar o fato de que a tradição jurídica latino-americana se constituiu a partir de uma evidente tendência de judicialização dos conflitos, confiando-se ao Estado o monopólio da produção normativa e de aplicação das leis; por outro lado, a judicialização não se tem constituído num impedimento para o desenvolvimento dos meios de Resolução Alternativa de Litígios (ADR) no continente. Gabriela Szlak (2012, p. 517) cita algumas hipóteses que explicam essa aparente contradição: os altos custos dos processos judiciais, a demora para obtenção de sentenças e um elevado grau de desconfiança da população local em relação do funcionamento do Poder Judiciário podem justificar uma tendência de se recorrer a formas extrajudiciais de resolução de litígios. Embora não se possa afirmar de maneira categórica que os meios Alternativos de Resolução de Controvérsias (ADR) são hoje uma realidade na América Latina, o cenário que se descortina para o continente é bastante promissor. A despeito da inexistência de uma literatura mais robusta sobre o tema, a América Latina nada mais faz senão reproduzir uma tendência mundial de utilização tantos dos meios Alternativos de Resolução de Litígios (ADR) quanto, com o advento das novas tecnologias, dos meios de Resolução Online de Conflitos (ODR), como afirmam Mercedez Albornoz e Nuria Martín (2013, p. 42):

\begin{abstract}
A literatura existente sobre o estado de ODR na América Latina é muito escassa. Uma contribuição recente de Gabriela R. Szlak lida com os desafios e oportunidades de ODR na região. Ela toma como certo que ODR é apropriado para esses países em desenvolvimento, e, tendo descrito a paisagem regional, prevê um futuro promissor para a implementação do ODR. Nosso trabalho discute este estudo e constata que a nossa própria posição geralmente adere à previsão de Szlak. ${ }^{8}$
\end{abstract}

O exemplo brasileiro é emblemático. Tradicionalmente, o Brasil sempre enfrentou enormes resistências para a utilização dos meios de Resolução Alternativa de Litígios. O passar dos anos, contudo, revelou uma mudança significativa na maneira como os profissionais do direito, juízes, advogados e servidores do judiciário concebiam os ADR. A conciliação, a mediação e a arbitragem passaram a ser vistas como formas eficazes de diminuição do número excessivo de processos que tramitam no Poder Judiciário. A própria arbitragem, antes submetida ao crivo e à chancela do judiciário - o que dela retirava toda e qualquer possibilidade de ser considerada mais vantajosa em relação à judicialização direta dos conflitos -, tornou-se reconhecida como um meio importante de resolução de litígios. Esse foi, contudo, um processo lento. A Lei de Arbitragem brasileira, Lei $n^{\circ}$ 9.307, data de 1996, e apenas em julho de 2002 o Brasil ratificou a Convenção de New York sobre o Reconhecimento e a Execução de Sentenças Arbitrais Estrangeiras, de 1958, promulgada no Brasil pelo Decreto n 4.311, de 23 de julho de 2002.

Tais mudanças ocorreram por primeiro no âmbito do próprio Poder Judiciário. O elevado número de processos tramitando em todas as instâncias do judiciário brasileiro fez com que, em novembro de

\footnotetext{
8 "The existing literature on the state of ODR in Latin America is very scarce. A recent contribution by Gabriela R. Szlak deals with the challenges and opportunities of ODR in the region. She takes for granted that ODR is appropriate for these developing countries, and having described the regional landscape, she forecasts a promising future for ODR implementation. Our paper discusses this study and finds that our own position generally adheres to Szlak's prediction."
} 
2010, o Conselho Nacional de Justiça (CNJ) editasse a Resolução $n^{\circ} 125$, instituindo a Política Judiciária Nacional de tratamento dos conflitos de interesses. Segundo a Resolução, os órgãos integrantes do Poder Judiciário ficaram obrigados a criar mecanismos de resolução de litígios, recorrendo aos meios consensuais de negociação, como a conciliação e a mediação. Para tanto, os tribunais deveriam criar os Núcleos Permanentes de Métodos Consensuais de Resolução de Conflitos e os Centros Judiciários de Solução de Conflitos e Cidadania, estes últimos encarregados de efetuar a mediação pré-processual, sendo compostos por mediadores e conciliadores treinados e credenciados junto aos tribunais (PEREIRA, 2015). Essas preocupações também se refletiram na legislação processual. O novo Código de Processo Civil Brasileiro, Lei $n^{\circ} 13.105$, de 16 de março de 2015, erigiu o recurso à mediação e à conciliação como procedimento estritamente obrigatório e necessário para a resolução de conflitos, uma importante mudança paradigmática. $\mathrm{O}$ art. $3^{\circ}$ desta lei assim estabelece:

\footnotetext{
Art. $3^{\circ}$ Não se excluirá da apreciação jurisdicional ameaça ou lesão a direito.

$\S 1^{\circ}$ É permitida a arbitragem, na forma da lei.

$\S 2^{\circ} \mathrm{O}$ Estado promoverá, sempre que possível, a solução consensual dos conflitos.

$\S 3^{\circ} \mathrm{A}$ conciliação, a mediação e outros métodos de solução consensual de conflitos deverão ser estimulados por juízes, advogados, defensores públicos e membros do Ministério Público, inclusive no curso do processo judicial.
}

Em junho de 2015, a legislação brasileira deu um salto definitivo em direção à adoção dos mecanismos extrajudiciais de resolução de conflitos, rompendo a última barreira existente. A Lei n 13.140 dispôs sobre a mediação entre particulares como meio de solução de controvérsias e sobre a autocomposição de conflitos no âmbito da Administração Pública. O art. 32 da lei estabelece:

\footnotetext{
A União, os Estados, o Distrito Federal e os Municípios poderão criar câmaras de prevenção e resolução administrativa de conflitos, no âmbito dos respectivos órgãos da Advocacia Pública, onde houver, com competência para:

I - dirimir conflitos entre órgãos e entidades da administração pública;

II - avaliar a admissibilidade dos pedidos de resolução de conflitos, por meio de composição, no caso de controvérsia entre particular e pessoa jurídica de direito público;

III - promover, quando couber, a celebração de termo de ajustamento de conduta
}

A possibilidade de se submeter os litígios na Administração Pública aos procedimentos próprios dos meios de Resolução Alternativa de Conflitos transpõe a última, e talvez mais significativa, barreira para o desenvolvimento dos ADR no Brasil, uma vez que boa parte dos processos judiciais atualmente em trâmite nos tribunais brasileiros tem como partes os cidadãos e as várias esferas da Administração Pública.

Dentre os diversos conflitos que podem envolver os cidadãos e a Administração Pública, os que se apresentam de forma mais dramática, em razão do bem jurídico que se pretende proteger, são as demandas por prestação de serviços de saúde. No Brasil, a judicialização de demandas relativas à prestação de serviços de saúde cresceu significativamente nos últimos dez anos, suscitando uma preocupação corrente dos gestores públicos e da população.

A competência para a prestação dos serviços de saúde no Brasil é repartida entre a União Federal, os Estados e os Municípios, conforme estabelece o Art. 23, II da Constituição Federal Brasileira. Isso significa dizer que os três entes da Federação podem formular e executar as políticas de saúde no país. Para evitar a sobreposição de competências, a Lei Federal $n^{\circ}$ 8.080/90, denominada Lei Orgânica da Saúde, estruturou o Sistema Único de Saúde (SUS).

Apesar dos esforços dos poderes públicos federal, estadual e municipal, as dificuldades de operação e gestão do Sistema Único de Saúde (SUS) conduziram a um crescimento vertiginoso do número de ações judiciais em trâmite nos tribunais brasileiros. Tais ações têm como objeto a prestação de serviços básicos de assistência à saúde, como o fornecimento de medicamentos e a realização de intervenções cirúrgicas 
Em pesquisa realizada pelo Conselho Nacional de Justiça do Brasil (CNJ), foram detectados inúmeros obstáculos para a concretização das políticas de saúde. Dentre esses obstáculos destacam-se: a) a desarticulação da rede de assistência local; b) baixa comunicação dentro dos próprios setores internos das Secretarias Saúde; c) ausência de diálogo entre as instituições jurídicas e políticas; d) ausência de espaço físico e de canais de entrada para acolher as demandas da população administrativamente; e) baixa qualificação profissional dos gestores e profissionais de saúde; f) grande número de conflitos envolvendo a prestação de serviços públicos de saúde Essa realidade é comum às várias regiões do país e se agrava no Nordeste brasileiro, em razão dos baixos índices de desenvolvimento humano (IDH) e de saneamento básico da região. Registre-se que a maior parte das ações judiciais é patrocinada pelas Defensorias Públicas, que prestam assessoria jurídica à população de baixa renda que depende dos serviços estatais e não tem recursos para buscar a assistência privada à saúde.

A pesquisa do $\mathrm{CNJ}$ identificou, contudo, algumas experiências exitosas de resolução dos conflitos de saúde, chegando à conclusão de que o modelo adversarial não é o mais indicado para a resolução do problema. Iniciativas de resolução extrajudicial dos litígios produzem resultados muito mais céleres e satisfatórios, uma vez que envolvem todos os atores institucionais no processo decisório, evitando-se, com isso, o recurso ao Poder Judiciário.

Observe-se que a legislação brasileira não menciona o uso dos meios de Resolução Online de Litígios (ODR), referindo-se apenas aos meios mais tradicionais de resolução extrajudicial de controvérsias. Em matéria de relações consumo, contudo, algumas experiências importantes têm sido desenvolvidas. A plataforma Consumidor.gov.br, por exemplo, tem apresentado uma razoável índice de resolução de conflitos. O sítio fornece um quadro de indicadores estatísticos sobre o serviço prestado, com informações e gráficos sobre o tempo médio de respostas das empresas, grau de satisfação do consumidor e índice de resolução das reclamações. Em 21 de outubro de 2015, o sítio contava com 280 empresas, 162.561 usuários cadastrados e 173.453 reclamações finalizadas.

O objetivo da plataforma, que começou a funcionar em maio de 2014, é promover a resolução alternativa de conflitos de consumo por meio da Internet, permitindo uma interlocução direta entre consumidores e empresas. A vantagem da plataforma em relação a outros sistemas de Resolução Online de Conflitos de consumo disponíveis no Brasil decorre do fato de que se trata de uma iniciativa estatal. Dessa forma, apenas podem participar as empresas que voluntariamente se vinculam ao programa e assinam um termo de compromisso, no qual se obrigam a fornecer uma solução para o conflito no prazo máximo de dez dias:

\footnotetext{
Por se tratar de um serviço provido e mantido pelo Estado, com ênfase na interatividade entre consumidores e fornecedores para redução de conflitos de consumo, a participação de empresas no Consumidor.gov.br, só é permitida àqueles que aderem formalmente ao serviço, mediante assinatura de termo no qual se comprometem em conhecer, analisar e investir todos os esforços disponíveis para a solução dos problemas apresentados. O consumidor, por sua vez, deve se identificar adequadamente e comprometer-se a apresentar todos os dados e informações relativas à reclamação relatada. (CONSUMIDOR. GOV. BR, INTERNET).
}

No entanto, a criação de uma plataforma online para resolução não apenas dos litígios decorrentes das relações de consumo, como também de conflitos envolvendo os cidadãos e a Administração Pública, pode tornar mais rápido e eficaz o processo resolução do litígio, permitindo um acesso mais rápido à justiça, medida fundamental quando se trata de garantir à população o respeito aos seus direitos fundamentais.

\section{As novas tecnologias da informação e comunicação: suportes para a resolução online de litígios}

O desenvolvimento dos meios de Resolução Online de Litígios (ODR) está intimamente associado ao aprimoramento das tecnologias de informação e transmissão de dados ( $\mathrm{TI})$. Tal fato decorre de dois fatores fundamentais. O primeiro deles diz respeito às dificuldades enfrentadas pelos meios de Resolução 
Alternativa de Controvérsias (ADR) - dos quais o ODR é uma faceta - no que concerne à regulação dos conflitos oriundos das relações online. No momento em que a transmissão e difusão de dados numéricos ultrapassa as fronteiras físicas entre os países, encurtando distâncias e aproximando os indivíduos, resta evidente que os processos tradicionais de que fazem uso os meios de Resolução Alternativa de Conflitos tornam-se cada vez mais irrelevantes, quiçá obsoletos. Assim ocorre porque os ADR fundamse basicamente na resolução de conflitos face-a-face, ou F2F (face-to-face), tornando o acesso a esses meios de resolução de litígios por vezes inacessível do ponto de vista econômico. As longas distâncias que podem separar os litigantes inviabiliza o recurso aos meios tradicionais de resolução de controvérsias, sejam tais meios jurisdicionais ou não. E tais dificuldades influenciam diretamente na escolha da jurisdição e da legislação mais adequadas para a resolução do litígio.

O segundo fator que vincula o desenvolvimento dos meios de Resolução Online de Litígios às tecnologias de informação e comunicação decorre das imensas possibilidades abertas pelas redes numéricas. A simples ocultação da identidade de um usuário na rede põe em relevo a dificuldade de manutenção do princípio da confiança, que deve assegurar a efetividade do sistema de resolução extrajudicial de conflitos. Além disso, as redes numéricas evidenciaram diferenças linguísticas e culturais que opõem não apenas os litigantes, como também demarcam o território dos diversos sistemas jurídicos, uma oposição que não assumia relevância quando as disputas estavam circunscritas a uma mesma base territorial e jurisdicional. Tais fatores conduziram inevitavelmente ao desenvolvimento daquilo que se convencionou denominar Resolução Online de Litígios (ODR). Em um primeiro momento, o termo fazia referência à utilização dos recursos da tecnologia de informação na resolução extrajudicial de litígios, aproximando ADR e TI, em especial nos conflitos originários de relações virtuais. Num segundo momento, a utilização da tecnologia passou a ser empregada também nos conflitos ocorridos off-line.

A despeito da necessária aproximação entre os modos extrajudiciais de resolução de controvérsias (ADR) e as tecnologias de informação e transmissão de dados ( $\mathrm{TI}$ ), do ponto de vista teórico ainda existe certa dissociação entre dois campos específicos dos ADR: a Resolução Online de Litígios (ODR) e o Dispute Systems Design (DSD). Em seu estágio inicial, o DSD surgiu como uma tentativa de estabelecer parâmetros específicos para a resolução de litígios, definindo-lhe os limites físicos, profissionais e conceituais. Noutros termos, por DSD deve-se entender a tentativa de compreender como as diferentes modalidades de ADR poderiam ser utilizadas de maneira mais efetiva no âmbito de uma organização, fixando procedimentos e critérios para a sua implantação (RABINOVICH-EINY; KATSH, 2012, p. 167). A idealização de sistemas para a resolução de conflitos nem sempre deu especial atenção à utilização da tecnologia. De igual modo, os modos de Resolução Online de Litígios também nem sempre estabeleceram uma distinção, importante do ponto de vista conceitual, entre as ferramentas de resolução de conflitos e os sistemas nos quais essas ferramentas estão sendo utilizadas. Como se verá a seguir, ODR e DSD podem estabelecer uma relação de imbricação e influência recíproca, contribuindo assim para o desenvolvimento de ambos.

\section{ODR e Dispute Systems Design (DSD): uma necessária aproximação}

Orna Rabinovitch-Einy e Ethan Katsh (2012, p. 40) dividem o quadro atual da Resolução Online de Litígios em dois domínios específicos: ferramentas (tools) e sistemas (systems). Essa distinção, nem sempre efetuada pelos especialistas, assume uma significativa relevância teórica, uma vez que funciona como marco distintivo entre duas concepções de ODR que, embora à primeira vista possam parecer indissociáveis, apresentam características que as diferenciam.

O primeiro domínio compreende o desenvolvimento de aplicativos e ferramentas capazes de resolver os litígios, quer estes ocorram online, quer sejam oriundos de relações off-line. Nesse sentido, os modos de Resolução Online de Conflitos (ODR) não são percebidos como um campo autônomo e independente, constituindo antes um sistema de suporte para que árbitros e mediadores possam fornecer soluções mais rápidas e eficazes para os conflitos. O uso da tecnologia, nesses casos, transforma os 
softwares em ferramentas capazes de aprimorar e otimizar os processos tradicionais de resolução de litígios (RABINOVICH-EINY; KATSH, 2012, p. 41). Tais ferramentas podem assumir feições as mais variadas, como, por exemplo, os softwares que permitem uma negociação automatizada, na qual árbitros e mediadores são substituídos por um programa que gerencia os processos de tomada de decisões. A terceira parte no processo de negociação, ou seja, o mediador, árbitro ou conciliador, é então substituída por uma máquina virtual. Outros exemplos de ferramentas são os sistemas de suporte para negociação, que auxiliam os litigantes na fixação e determinação dos seus interesses, maximizando os ganhos de ambos, e as plataformas online de resolução de conflitos, que criam um ambiente para a negociação e troca de informações e documentos.

O segundo domínio diz respeito aos sistemas de ODR. Tais sistemas fazem uso das ferramentas de resolução online de conflitos, mas são desenvolvidos para ordenar e coordenar a resolução de disputas envolvendo um número relativamente limitado, porém potencialmente expansível, de usuários que podem vivenciar experiências similares, como ocorre com as comunidades virtuais. O exemplo mais evidente desse tipo de sistema é o mecanismo de resolução de controvérsias desenvolvido para o sítio e-Bay. A partir do estudo e da análise dos conflitos originados das relações jurídicas firmadas no sítio do e-Bay, o sistema permite a padronização de procedimentos para a resolução em larga escala dos conflitos, obtendo um elevado índice de sucesso. Ambas as dimensões do ODR sempre apresentaram um certo distanciamento em relação ao Dispute System Design (DSD). No entanto, resta evidente que tanto as ferramentas quantos os sistemas de ODR transformaram os limites conceituais não apenas dos meios de Resolução Alternativa de Litígios (ADR), como também alteraram em definitivo a maneira como o Dispute System Design (DSD) concebe as rotinas e métodos de resolução de conflitos.

O design de sistemas para a resolução de conflitos, DSD, identifica três diferentes formas de resolução de um conflito. Pode-se fazê-lo conciliando-se os litigantes a partir da fixação dos seus interesses recíprocos; pode-se determinar quem tem razão ou, ainda, pode-se estabelecer quem tem mais poder. No primeiro caso, a resolução baseia-se na conciliação. No segundo caso, o problema é resolvido recorrendose aos tribunais. Na terceira hipótese, as relações de poder entre os litigantes são resolvidas com o uso de medidas de força, como as greves ou, nos casos extremos, as guerras (RABINOVICH-EINY; KATSH, 2012, p. 44). É evidente que a abordagem fundada na análise dos interesses dos litigantes apresenta custos menores em relação às demais e o design do sistema de resolução de conflitos objetiva estabelecer a melhor relação possível entre as vantagens e desvantagens de se adotar cada uma dessas abordagens.

As novas tecnologias, portanto, exerceram um forte impacto sobre o Dispute System Design (DSD), alterando os seus paradigmas e expandindo os limites profissionais, físicos e conceituais que a teoria do DSD estabeleceu ao longo das últimas décadas. A necessidade de fornecer uma resolução eficiente para os litígios ocorridos no âmbito das organizações provocou o surgimento de uma vasta gama de especialistas na gestão de conflitos. No entanto, com o advento das tecnologias digitais de transmissão de dados, conciliadores, mediadores, árbitros, ombudsmen e outros profissionais, antes habituados a desenvolver os sistemas de resolução de controvérsias fundando-os em relações face-a-face, passaram a ter de lidar com um novo e desconhecido universo de problemas.

$\mathrm{Na}$ medida em que as tecnologias digitais foram incorporadas à vida cotidiana das pessoas, a resolução dos conflitos originários do ambiente virtual exigiu dos profissionais uma familiaridade com as oportunidades e os perigos que o uso da comunicação digital pode acarretar para a prevenção e resolução de litígios (RABINOVICH-EINY; KATSH, 2012, p. 48). Em razão disso, os designers de sistemas de resolução de conflitos viram-se na desconfortável situação, para alguns, de ter de interagir com os especialistas e técnicos em computação. Esse é, contudo, um caminho sem volta. O desconforto de alguns desses profissionais não se restringe apenas ao uso das ferramentas tecnológicas, uma vez que o uso da tecnologia põe em cheque o próprio exercício de determinadas atividades. Os sistemas de solução de conflitos (DSD) podem até mesmo prescindir da intermediação humana na resolução do litígio, como ocorre nos casos das negociações automatizadas. E essa não é uma questão nova. $\mathrm{O}$ caráter disruptivo 
das tecnologias sempre colocou em cheque a existência de determinadas atividades profissionais, e não seria diferente com os especialistas em DSD.

Fenômeno semelhante ocorre em relação aos limites físicos da resolução de conflitos. A teoria tradicional do DSD consagrava a necessidade de se reservar um espaço físico específico para a resolução do conflito, separando-o do restante da estrutura organizacional da empresa, por exemplo (RABINOVICHEINY; KATSH, 2012, p. 51). Tal medida tinha por objetivo preservar o sigilo e a integridade das informações trocadas ao longo do processo de resolução do litígio. Na transposição do processo de resolução do conflito do ambiente físico para o ambiente virtual, essa fronteira física deixa de existir. A superação dessa barreira física acarreta, por um lado, um enfraquecimento da confidencialidade do processo de mediação e conciliação. Por outro lado, a introdução dos métodos de ODR alterou significativamente as expectativas das partes e do próprio ambiente organizacional em relação à confidencialidade.

A vantagem da utilização dos meios de Resolução Alternativa de Litígios (ADR) residia basicamente na possibilidade de se manter o sigilo do processo, preservando os interesses das partes e da própria empresa. O sacrifício dessa confidencialidade, em nome da utilização dos recursos tecnológicos no processo de resolução do conflito, é, no entanto, compensado com um ganho nos mecanismos de controle dos procedimentos adotados, tornando a resolução do litígio mais justa e equânime. $O$ fato de as partes poderem ter acesso imediato a todas as comunicações trocadas entre elas e a terceira parte (conciliador, mediador ou árbitro) dota o procedimento de maior segurança, em especial no que diz respeito à legitimidade e justiça do resultado final obtido. Além disso, em alguns litígios o componente emocional dos envolvidos tem menor significância, fazendo com que o recurso a sistemas digitais de resolução seja mais vantajoso, ainda que com pequeno sacrifício do sigilo e da confidencialidade da troca de informações.

As novas tecnologias, portanto, modificaram substancialmente os aspectos conceituais do Dispute System Design, rompendo com as categorizações estanques e imutáveis entre o que poderia e o que não poderia ser considerado ADR. Tais barreiras conceituais desenvolvidas no âmbito do DSD estão sendo alteradas. Distinções tradicionais entre procedimentos formais e informais ou entre resolução e prevenção de conflitos estão sendo revisadas. A principal dessas alterações reside na introdução da tecnologia como quarta parte no processo decisório. Em alguns casos, até mesmo a terceira parte, formada pelo elemento humano materializado no conciliador, no mediador ou no árbitro, pode ser substituída pelos recursos tecnológicos, como ocorre com as negociações automatizadas. Nessas situações, o Dispute Design System (DSD) tem um papel fundamental. A inteligência artificial deve, portanto, ser considerada como um importante elemento a ser incorporado à resolução de litígios, com implicações talvez jamais vistas tanto para o Direito Interno dos países, quanto para o próprio Direito Internacional.

\section{ODR e inteligência artificial: a construção de um suporte de negociação inteligente}

Aideia de que um sistema informatizado possa não apenas regular, mas, sobretudo, fornecer respostas satisfatórias para um litígio ainda encontra muitas reservas na comunidade jurídica. Tal resistência deve-se em parte à natural recusa dos seres humanos em submeter questões cruciais de suas vidas, que não raro envolvem julgamentos axiológicos e escolhas morais, à decisão de uma máquina. Além disso, os humanos não se sentem confortáveis com a possibilidade de que uma máquina possa substituir peritos humanos nos processos de tomada de decisões, seja por temerem que as máquinas decidam de maneira errada, seja, ao revés, por recearem que as máquinas possam não apenas tomar tais decisões como também estar aptas para fazê-lo de maneira mais eficaz do que os próprios humanos (ANDRADE; CARNEIRO; NOVAIS, 2010, p. 02). O medo da substituição do homem pela máquina não é recente e tem sido tema recorrente nas obras de ficção científica na literatura e no cinema. A questão a saber é até que ponto esse receio é infundado e de que maneira a utilização da inteligência artificial na resolução de litígios pode se constituir num avanço fundamental para os sistemas de ODR. 
A inteligência artificial pode ser definida como a "[tentativa de] resolver por computador qualquer problema, que um ser humano pode resolver, mais rápido" (LODDER; THIESSEN, 2003). ${ }^{9}$ Considerando a incorporação das tecnologias nos processos de resolução online de litígios, Francisco Andrade, Davide Carneiro e Paulo Novais (2010, p. 02) identificam duas gerações de ODR. Na primeira geração, o uso da tecnologia não prescinde da intervenção humana. O ser humano continua a ser o elemento central no planejamento e na tomada de decisão. As tecnologias, quando utilizadas, assumem um papel meramente auxiliar e de menor relevância, facilitando apenas a gestão e a troca de informações entre as partes e entre estas e o terceiro neutro mediador do conflito. Em tais situações, os recursos tecnológicos mais utilizados são a troca de mensagens eletrônicas, as salas de conversas eletrônicas (chats) e a vídeo conferência. Em todos esses casos, a tecnologia não passa de mero auxiliar do mediador, do conciliador ou do árbitro, não possuindo qualquer autonomia no processo decisório.

Asegunda geração de ODR, no entanto, encontra ainda grandes dificuldades no seu desenvolvimento, uma vez que preconiza uma autonomia crescente da tecnologia nos processos de tomada de decisões e, como já visto, esbarra na reticência com que os humanos consideram a possibilidade de que máquinas possam decidir de maneira autônoma e independente sobre conflitos envolvendo seres humanos. Ainda assim, uma segunda geração de ODR vem utilizando com uma incidência cada vez maior a inteligência artificial e outros recursos tecnológicos como elementos fundamentais para a Resolução Online de Litígios. A diferença nesse novo cenário resulta do fato de que a tecnologia assume um protagonismo no processo decisório, diminuindo e até mesmo afastando a participação tanto das partes em litígio quanto do terceiro neutro.

A intervenção humana é substituída por agentes de softwares inteligentes que assumem a capacidade de decisão e resolução do conflito. Tais agentes são dotados do conhecimento e da autonomia necessários para representar, interpretar e emular os desejos, as intenções e as emoções humanas. Essa não é, contudo, uma tarefa tão simples, pois envolve a integração das tecnologias de comunicação com outras áreas do conhecimento, a exemplo da Filosofia, da Matemática e da Inteligência Artificial, além do desenvolvimento de produtos oriundos dessas áreas, como as "[...] redes neuronais, agentes inteligentes, raciocínio baseado em casos, dedução lógica, argumentação, métodos para raciocínio com base em informação incompleta e para aprendizagem" (ANDRADE; CARNEIRO; NOVAIS, 2010, p. 07). Esses recursos podem ser utilizados pelos sistemas de ODR, e alguns deles certamente o são.

Os Sistemas Multi-Agente, por exemplo, constituem a reunião dos elementos da Inteligência Artificial com os Modelos Computacionais Distribuídos, gerando a denominada inteligência artificial distribuída:

Um sistema multi-agente é constituído por um grupo de entidades (software e hardware) capaz de percepcionar a realidade envolvente e de tomar decisões inteligentes em ordem à realização de um objectivo comum (como seja o de propor uma solução às partes em litígio). (ANDRADE; CARNEIRO; NOVAIS, 2010, p. 08).

A ideia subjacente ao conceito de Sistema Multi-Agente consiste na necessária integração entre os agentes de software e o ambiente no qual tais agentes atuam. Os agentes apresentariam algumas capacidades e propriedades específicas que variam de acordo com caráter forte ou fraco do agente de software. Propriedades como autonomia, sociabilidade, reatividade e proatividade caracterizam os chamados agentes de software fracos, que se tornariam agentes de software fortes quando a eles fossem adicionadas outras propriedades e aptidões como mobilidade, veracidade, benevolência e racionalidade. No primeiro caso, o agente de software é capaz de tomar decisões autonomamente a partir da interação com outros agentes, avaliando a circunstâncias ambientais da negociação e reagindo, sem a interferência humana, às mudanças de cenário. No segundo caso, os agentes de software fortes serão capazes não apenas de tomar decisões de maneira independente como também terão a capacidade de

\footnotetext{
"[...] trying to solve by computer any problem, that a human can solve, faster".
} 
se movimentar numa rede de comunicação, não fornecendo informações falsas e não estabelecendo objetivos contraditórios. Como afirmam Francisco Andrade, Davide Carneiro e Paulo Novais (2010, p. 09):

Este paradigma rapidamente começou a desempenhar um papel de relevo no desenho dos sistemas inteligentes, tendo sido levada a cabo investigação no domínio da argumentação nas tecnologias de 'agentes'. Os 'agentes' utilizam argumentos, debatem, defendem as suas crenças, tentam convencer os outros 'agentes' a aderir às suas crenças. No âmbito do ODR isto torna-se particularmente útil, já que argumentação e debate são elementos centrais de qualquer processo de resolução de litígios.

Os Sistemas Multi-Agentes não são os únicos recursos tecnológicos que a inteligência artificial põe à disposição dos modos de Resolução Online de Litígios. O uso dos sistemas especialistas ou das chamadas interfaces inteligentes também se revelam bastante promissores. O exemplo mais comum desse tipo de interface são os sistemas de busca na Internet, que fornecem ferramentas de auxílio à busca, completando e corrigindo as informações prestadas pelo usuário e fornecendo o resultado que mais se aproxima das suas intenções.

Os Sistemas de Suporte à Decisão (Decision Suport systems) possibilitam o gerenciamento da quantidade de informação recebida pelas partes, sendo úteis no planejamento do processo de resolução do conflito. Tais sistemas podem utilizar outras ferramentas na gestão do conhecimento e da informação como:
1) Rule-based reasoning (raciocínio baseado em regras), no qual o conhecimento de um domínio específico é representado como um conjunto de regras na forma 'se <condição(ões)> então ação/ conclusão';
2) Case-based reasoning (raciocínio baseado em casos), que utiliza a experiência anterior para analisar e resolver um novo problema, explicando porque as experiências prévias são ou não semelhantes ao problema atual e adaptando as soluções do passado para atender às exigências do presente;
3) Machine learning (aprendizado da máquina), no qual o sistema de inteligência artificial tenta aprender novos conhecimentos automaticamente;
4) Neural networks (redes neurais). Uma rede neural consiste em vários elementos de processamento auto-ajustável, cooperando em uma rede densamente interconectada. Cada elemento de processamento gera um único sinal de saída que é transmitido para os demais elementos de processamento. O sinal de saída de um elemento de processamento depende da entrada para esse elemento de processamento: cada entrada é balizada por um fator de ponderação que determina o grau de influência que a entrada terá para a saída. A força do fator de ponderação é ajustada autonomamente pelo elemento de processamento, à medida que os dados são processados. (LODDER; ZELEZNIKOW, 2012, p. 63).

A aplicação desses recursos à Resolução Online de Conflitos recorre por vezes à Teoria dos Jogos, como nos casos dos sistemas Adjust Winner e Smartsettle, que utilizam algoritmos matemáticos para determinar que desejos e intenções das partes podem ser negociados e "divididos" de acordo com um ranking previamente estabelecido. Tais ferramentas são até mesmo utilizadas na resolução de conflitos internacionais. O algoritmo desenvolvido para o Adjust Winner foi utilizado na disputa territorial que envolveu a China, Taiwan e quatro membros da Associação das Nações do Sudeste Asiático (ASEAN), Vietnã, Filipinas, Malásia e Brunei. O conflito dizia respeito às áreas de terra firma e águas circundantes das Ilhas Spratly (um grupo de mais de 230 pequenas ilhas e recifes no Mar da China), nas quais acreditava-se haver depósitos de petróleo e gás. O mesmo algoritmo foi também aplicado nas negociações do tratado do Canal do Panamá e nos acordos de Camp David, além das negociações entre israelenses e palestinos (LODDER; ZELEZNIKOW, 2012, p. 76).

Como se observa, a utilização da inteligência artificial na resolução de litígios não se constitui em cenário de ficção científica, embora os atuais recursos de IA ainda estejam muito aquém de representar a imagem que deles foi criada pela literatura e pelo cinema. O famoso teste de Turing para verificar o grau de inteligência de um programa ainda continua válido, apesar de algumas ressalvas. Segundo o teste, 
desenvolvido em 1950, se uma pessoa conversar com uma máquina durante um certo lapso temporal, sem saber que se trata de uma máquina, e acreditar que estava a conversar com um humano, então o programa passou no teste e pode ser qualificado como inteligente. Contudo, o teste merece reparos, Deve-se levar em conta o grau de expectativas e de crenças do sujeito em relação aos computadores, pois a possibilidade do erro constitui uma expectativa natural na avaliação do comportamento humano que não se espera possa existir em relação à atuação das máquinas. Será, portanto, considerada inteligente a máquina que conseguir emular o comportamento humano com todas as suas imperfeições. $\mathrm{O}$ uso de máquinas pensantes para a resolução de litígios traz consigo implicações éticas e jurídicas para as quais o Direito deve fornecer respostas.

\section{Conclusão}

Transportados para a Resolução Online de Conflitos (ODR), tais problemas assumem outra dimensão e têm um impacto decisivo nas ordens jurídicas internas estatais e em suas regras de conflitos de leis e de jurisdições. Em primeiro lugar, porque a resolução desses litígios terminará quase sempre com um acordo que assume a feição e a forma de um contrato. Em segundo lugar, não se deve desconsiderar o fato de que as partes que recorrem aos modos de Resolução Extrajudicial de Litígios pretendem, antes de tudo, evitar a submissão do conflito ao juiz estatal, razão pela qual as normas do Direito interno dos Estados, reguladoras da jurisdição internacional, não seriam consultadas. A decisão proferida pelo terceiro neutro, ou mesmo o acordo firmado pelas partes sem a intervenção do conciliador, do mediador ou do árbitro, não produzirá, a rigor e de acordo com a orientação adotada por cada ordem jurídica em particular, os efeitos de coisa julgada. O descumprimento do acordo firmado ao término da resolução do conflito, no entanto, pode conduzir a dois tipos distintos de execução: uma execução forçada pela via judicial e uma execução forçada pela via extrajudicial. E será no âmbito da execução dessas decisões que reside a maior fragilidade dos sistemas de ODR.

Nos casos de litígios que ultrapassam as fronteiras jurisdicionais dos países, por apresentarem um elemento de extraneidade, a execução forçada pela via judicial ensejará uma tomada de posição da autoridade jurisdicional em relação ao reconhecimento desses acordos. Esse tipo de procedimento é normalmente evitado pelas partes, uma vez que não lhes interessaria submeter o litígio à apreciação do juiz estatal. Além disso, os aspectos extraterritoriais que envolvem o conflito dificultam significativamente 0 recurso aos meios judiciais para que a decisão seja efetivamente cumprida. Em tais casos, há evidentemente um déficit de eficácia da resolução alcançada, uma vez que as partes terão de levar em conta as vantagens e desvantagens econômicas de se submeter o acordo a uma determinada jurisdição estatal, considerando inclusive a aplicação das regras internas de fixação da competência jurisdicional para regular a execução e, por óbvio, as normas materiais aplicáveis ao próprio processo de execução.

Algumas saídas para os impasses causados por tais situações têm sido buscadas pelos sistemas de ODR. Tais saídas dizem respeito à execução forçada extrajudicial dos acordos resultantes da Resolução Online do Conflito e essa execução conduz a adoção de medidas que, se por um lado evitam que as partes tenham de se submeter à jurisdição dos Estados para dotar tais acordos de eficácia, por outro lado essas medidas não se conformam ao quadro normativo mais tradicional em matéria de execução de decisões. A autoexecução tecnológica é uma dessas medidas e um dos exemplos desse tipo de solução é o adotado pelo Sistema de Resolução de Controvérsias sobre Nomes de Domínio na Internet (Uniform Dispute Resolution Policy - URDP) da ICANN (Internet Corporation for Assigned Names and Numbers). (TRAESCH, 2010, p. 365)

O controle do processo de execução da decisão proferida ao fim da Resolução Online do Conflito está centrado no organismo que detém os recursos e os meios tecnológicos para fazer cumprir a decisão. No caso dos nomes de domínio na Internet, a ICANN possui esses recursos, atribuindo à parte vencedora na demanda o domínio por ela reivindicado. 
É evidente que tal medida é aplicável em circunstâncias bastantes peculiares, uma vez que pressupõe que o organismo que gerencia o sistema de ODR esteja preparado para fazer cumprir automaticamente a decisão. Além disso, no caso da ICANN, o Estado norte-americano monitora as ações do órgão, retirandoIhe o caráter de organização exclusivamente profissional situada à margem dos poderes públicos estatais. No entanto, medidas similares vêm sendo utilizadas noutros casos, a exemplo das coerções técnicas, que impedem o download de um determinado arquivo de música ou de vídeo. Essas medidas possuem um alcance limitado, pois demandam de quem as aplica o controle técnico dos meios eletrônicos, o que nem sempre é possível.

Outras medidas de execução extrajudicial dos acordos de ODR podem assumir uma feição bem mais diversa. O sistema de resolução de litígios desenvolvido para o sítio Internet da empresa eBay foi pioneiro na utilização de uma ferramenta de avaliação do vendedor e do comprador a partir de alguns critérios pré-determinados, como confiabilidade das informações fornecidas, presteza no envio, qualidade do produto e adimplemento do pagamento. A avaliação das partes não se constitui, a rigor, em medida executória da decisão proferida no âmbito de um procedimento de Resolução Online de Conflitos. Seu objetivo principal consiste em incentivar os contratantes a cumprir o contrato, sob pena de perda da sua credibilidade no mercado.

A possibilidade de retenção do pagamento até que as obrigações contratuais sejam adimplidas fornece uma garantia maior ao consumidor. Esse procedimento é também utilizado por administradoras de cartão de crédito, tornando-se uma opção que desestimula o recurso aos modos de ODR, pois as partes, notadamente o consumidor, sempre se dão por satisfeitas com a possibilidade de devolução do dinheiro. Igual eficácia assumem as formas de pagamento que utilizam um terceiro neutro, que apenas libera a quantia para o vendedor quando o comprador autoriza essa liberação, dando por adimplidas as obrigações do fornecedor. A inclusão de cláusula contratual que obriga unilateralmente um dos contratantes, nesse caso o fornecedor do produto ou serviço, também pode se constituir em estímulo para o cumprimento das obrigações contratuais. Tem-se nesses casos um contrato unilateral, que cria um vínculo apenas para um dos contratantes, obrigando-o a cumprir o disposto no instrumento negocial.

As medidas aqui mencionadas não conferem diretamente um caráter coercitivo às decisões e acordos provenientes dos procedimentos de ODR. Tratam-se, na verdade, de medidas protetoras da parte mais frágil na relação negocial, o consumidor. No entanto, resta evidente que essas medidas apenas são aplicáveis a um tipo específico de relações jurídicas firmadas online, as relações de consumo. Mas não se pode dizer que possam ser estendidas a todas as relações jurídicas que se constituem nas redes numéricas. Existe, portanto, um amplo espectro de situações jurídicas para as quais a Resolução Online de Litígios pode não se constituir na via mais vantajosa do ponto de vista econômico, em razão das dificuldades de execução, judicial ou extrajudicial, de tais acordos.

\section{Referências}

ALBORNOZ, Maria Mercedes; MARTíN, Nuria González. Feasibility analysis of online dispute resolution in developing countries. Interamerican Law Review, Miami, v. 44, n. 1, p. 39-61, nov. 2013.

AMORIM, Fernando Sérgio Tenório de. Autonomia da vontade nos contratos eletrônicos internacionais de consumo. Curitiba: Juruá, 2008.

ARAUJO, Nadia de. Direito internacional privado. Rio de Janeiro: Renovar, 2003.

ARAUJO, Nadia de. Contratos internacionais: autonomia da vontade, Mercosul e convenções internacionais. Rio de Janeiro: Renovar, 1997.

BENYEKHLEF, Karim; GÉLINAS, Fabien. Online Dispute Resolution. Lex Electronica, Montréal, v. 10, n. 2, été/sum. 2005. Disponível em: <http://www.lex-electronica.org/articles/v10-2/Benyekhlef_Gelinas. pdf> Acesso em: 15 ago. 2015. 
BRAND, Ronald A. Party autonomy and access to justice in the UNCITRAL Online Dispute Resolution Project: legal studies research paper series. Pittsburg: University of Pittsburg, 2012. Disponível em: <http://ssrn.com/abstract=2125214 > Acesso em: 15 jul. 2015.

BRASIL. Conselho Nacional de Justiça. Judicialização da Saúde no Brasil: dados e experiências. Disponível em: <http://www.cnj.jus.br/files/conteudo/destaques/arquivo/2015/06/6781486daef02bc6ec8c1 e491a565006.pdf >. Acesso em: 08 jul. 2015.

BRASIL. Lei $\mathbf{n}^{0}$ 13.105, de 16 de março de 2015. Disponível em: <http://www.planalto.gov.br/ccivil_03/_ Ato2015-2018/2015/Lei/L13105.htm> Acesso em: 12 ago. 2015.

BRASIL. Lei no 13.140, de 26 de junho de 2015. Disponível em: <http://www.planalto.gov.br/ccivil_03/_ Ato2015-2018/2015/Lei/L13140.htm> Acesso em: 12 ago. 2015.

BRASIL. Secretaria Nacional do Consumidor. Consumidor.gov.br. Disponível em: <https://www. consumidor.gov.br/pages/principal/sobre-servico>. Acesso em: 21 out. 2015.

CASTETS-RENARD, Céline. Cours Droit de l'Internet. Paris: Montchrestien, 2010.

DU MARAIS, Bertrand. Autorégulation, régulation et co-régulation des réseaux. In: CHATILLON, Georges (Org.). Le droit International de I'Internet. Bruxelles: Bruyllant, 2002.

FAUVARQUE-COSSON, Bénédicte. Le Droit International Privé classique à l'épreuve des réseaux. In: CHATILLON, Georges. (Org.). Le droit International de I'Internet. Bruxelles: Bruyllant, 2002.

GELLMAN, Robert. A brief history of the Virtual Magistrate Project: the early months. Disponível em: < http://www.umass.edu/dispute/ncair/gellman.htm>. Acesso em: 20 ago. 2015.

GUILLEMARD, Sylvette. Le droit international privé face au contrat de vente cyberspatial. Disponível em: <http://www.theses.ulaval.ca/2003/20565/20565.html>. Acesso em: 13 jan. 2015.

GUTZWILLER, M. Le développement historique du droit international privé. In: Recueil des Cours, Den Haag, 1929. t. IV.

INTERNET CORPORATION FOR ASSIGNED NAMES AND NUMBERS (ICANN). Uniform domain name dispute resolution policy. Disponível em: <https://www.icann.org/resources/pages/policy-201202-25-en>. Acesso em: 12 set. 2015.

INTERNET CORPORATION FOR ASSIGNED NAMES AND NUMBERS (ICANN). Rules for uniform domain name dispute resolution policy (the "rules"). Disponível em: <https://www.icann.org/ resources/pages/udrp-rules-2015-03-11-en>. Acesso em: 12 set. 2015.

JAYME, Erik. Identité culturelle et intégration: le droit international privé postmoderne. Recueil des Cours, Collected Courses of the Hague Academy of International Law. Den Haag, Boston, 1995, v. 251, p. 9-267.

KATSH, Ethan; RIFIKIN, Janet. Online dispute resolution: resolving conflicts in cyberspace. San Francisco: Jossey-Bass, 2001.

KATSH, Ethan. ODR: a look at history. In: WAHAB, Mohamed S. Abdel; KATSH, Ethan; RAINEY, Daniel (Ed.). Online dispute resolution: theory and practice. A treatise on technology and dispute resolution. The Hague: Eleven International, 2012.

LAGARDE, Paul. Le nouveau droit international privé des contrats après l'entrée en vigueur de la convention de Rome du 19 juin de 1980. Revue Critique de Droit International Privé, Paris, n. 80, p. 287-340, avr./juin. 1991.

LONGWORTH, Elizabeth. Opportunité d'un cadre juridique applicable au cyberespace $-y$ compris dans une perspective Néo-Zélandaise. In: Les dimensions internationales du droit du cyberespace. Paris: Ed. UNESCO, 2000.

PEREIRA, Clovis Brasil. Conciliação e Mediação no Novo CPC. Disponível em: < http://www.conima. org.br/arquivos/4682 > Acesso em: 08 set. 2015. 
RABINOVICH-EINY, Orna; KATSH, Ethan. Digital Justice: reshaping boundaries in an online dispute resolution environment. International Journal of Online Dispute Resolution, v. 1, 2014. p. 05-36. Disponível em: < http://www.international-odr.com/first_issue >. Acesso em: 18 ago. 2015.

RABINOVICH-EINY, Orna; KATSH, Ethan. Lessons from online dispute resolution for Disputes Systems Design. In: WAHAB, Mohamed S. Abdel; KATSH, Ethan; RAINEY, Daniel (Ed.). Online dispute resolution: theory and practice. A treatise on technology and dispute resolution. The Hague: Eleven International, 2012.

RABINOVICH-EINY, Orna; KATSH, Ethan. Technology and dispute systems design. Harvard Negotiation Law Review, v. 17, n. 151, Spring, 2012.

RANOUIL, Véronique. L'autonomie de la volonté: naissance et évolution d'un concept. Paris: Presses Universitaries de France, 1980.

RULE, Colin. Online dispute resolution for business. San Francisco: Jossey-Bass, 2002.

RULE, Colin; SEN, Indu. Online dispute resolution and ombuds: bringing technology to the table. In: Journal of the International Ombudsman Association, Oakbrook Terrace, v. 8, n. 1, p. 76, 2015.

S.LAKSHMINARAYAN. Juridictions Compétentes et Internet. In : CHATILLON, Georges. (Org.). Le droit International de I'Internet. Bruxelles: Bruyllant, 2002.

STRENGER, Irineu. Autonomia da vontade em direito internacional privado. São Paulo: Revista dos Tribunais, 1968.

SZLAK, Gabriela R. Online Dispute Resolution in Latin America: Challenges and opportunities. In: WAHAB, Mohamed S. Abdel; KATSH, Ethan; RAINEY, Daniel (Ed.). Online dispute resolution: theory and practice. A treatise on technology and dispute resolution. The Hague: Eleven International, 2012.

TRUDEL, Pierre. L'influence de l'Internet sur la production du Droit. In: CHATILLON, Georges (Org.). Le droit International de I'Internet. Bruxelles: Bruyllant, 2002.

UNION EUROPÉENNE. Directive 2000/31/CE du Parlement Européen et du Conseil, du 8 Juin 200, relative à certains aspects juridiques des services de la société de l'information, et notamment du commerce électronique, dans le marché intérieur ("directive sur le commerce électronique»). Disponível em: < http://eurlex.europa.eu/LexUriServ/LexUriServ.do?uri=CELEX:32000L0031:fr:HTML>. Acesso em: 10 jul. 2015.

UNION EUROPÉENNE. Règlement (CE) N 44/2001 du Conseil concernant la compétence judiciaire, la reconnaissance et l'exécution des décisions en matière civile et commerciale. Disponível em:< http://publications.europa.eu> Acesso em: 06 jul. 2015.

UNION EUROPÉENNE. Regulamento UE n 1215/2012, do Parlamento Europeu e do Conselho, de 12 de dezembro de 2012, relativo à competência judiciária, ao reconhecimento e à execução de decisões em matéria civil e comercial (reformulação). Disponível em: < http://eur-lex.europa.eu/legalcontent/PT/ALL/?uri=CELEX:32012R1215 >. Acesso em: 06 jul. 2015.

UNION EUROPÉENNE. Regulamento (UE) N 524/2013 do Parlamento Europeu e do Conselho de 21 de maio de 2013 sobre a resolução de litígios de consumo em linha, que altera o Regulamento (CE) $n^{\circ}$ 2006/2004 e a Diretiva 2009/22/CE (Regulamento RLL). Disponível em: <http://eurlex.europa. eu/LexUriServ/LexUriServ.do?uri=OJ:L:2013:165:0001:0012:PT:PDF> Acesso em: 10 out. 2015.

UNITED NATIONS COMMISSION ON INTERNATIONAL TRADE LAW. A/CN.9/WG.III/WP.105.

Règlement des litiges en ligne dans les opérations internationales de commerce électronique.

Disponível em: <http://www.uncitral.org/uncitral/commission/working_groups/3Online_Dispute_

Resolution.html>. Acesso em: 10 ago. 2015.

UNESCO. Les dimensions internationales du cyberspace. Paris: Economica, 2000.

VALLERERSUNDI, Ana Palacio. In: CHATILLON, Georges (Org.). Le droit International de I'Internet. Bruxelles: Bruyllant, 2002. 
WAHAB, Mohamed S. Abdel; KATSH, Ethan; RAINEY, Daniel (Ed.). Online dispute resolution: theory and practice. A treatise on technology and dispute resolution. The Hague: Eleven International, 2012.

WING, Leah; RAINEY, Daniel. Online dispute resolution and the development of theory. In: WAHAB, Mohamed S. Abdel; KATSH, Ethan e RAINEY, Daniel (Ed.). Online dispute resolution: theory and practice. A treatise on technology and dispute resolution. The Hague: Eleven International, 2012.

Recebido em: 05/07/2016.

Aprovado em: 11/05/2017. 